\title{
Personality and taxonomy preferences, and the influence of category choice on the user experience for music streaming services
}

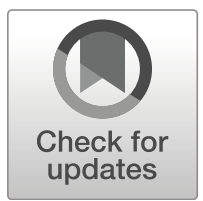

\author{
Bruce Ferwerda $^{1}$ (D) $\cdot$ Emily Yang $^{2} \cdot$ Markus SchedI $^{2} \cdot$ Marko Tkalcic $^{3}$
}

Received: 25 May 2018 / Revised: 17 January 2019 / Accepted: 4 February 2019 /

Published online: 27 February 2019

(C) The Author(s) 2019

\begin{abstract}
Music streaming services increasingly incorporate different ways for users to browse for music. Next to the commonly used "genre" taxonomy, nowadays additional taxonomies, such as mood and activities, are often used. As additional taxonomies have shown to be able to distract the user in their search, we looked at how to predict taxonomy preferences in order to counteract this. Additionally, we looked at how the number of categories presented within a taxonomy influences the user experience. We conducted an online user study where participants interacted with an application called "Tune-A-Find". We measured taxonomy choice (i.e., mood, activity, or genre), individual differences (e.g., personality traits and music expertise factors), and different user experience factors (i.e., choice difficulty and satisfaction, perceived system usefulness and quality) when presenting either 6- or 24-categories within the picked taxonomy. Among 297 participants, we found that personality traits are related to music taxonomy preferences. Furthermore, our findings show that the number of categories within a taxonomy influences the user experience in different ways and is moderated by music expertise. Our findings can support personalized user interfaces in music streaming services. By knowing the user's personality and expertise, the user interface can adapt to the user's preferred way of music browsing and thereby mitigate the problems that music listeners are facing while finding their way through the abundance of music choices online nowadays.
\end{abstract}

Keywords Personality · Taxonomy · Music · Categorization · Overchoice · Choice overload $\cdot$ Music sophistication

\section{Introduction}

The increasing volume of music imposes a cognitive challenge when users explore preferred music from a large collection. To overcome this, music streaming services try to organize their collections in such a way that users can easily browse and find what they would like

Bruce Ferwerda

bruce.ferwerda@ju.se

Extended author information available on the last page of the article. 
to hear. For this purpose, different categorization methods from music information retrieval (MIR) are used to organize music (for an overview see $[4,40]$ ).

Whereas, the "genre" taxonomy has been most commonly used to organize music, popular music streaming services, such as 8tracks (http://www.8tracks.com), AccuRadio (http:// www.accuradio.com), Songza (http://www.songza.com), Spotify (http://www.spotify.com), have started to provide additional, user-centric, taxonomies to better serve users with diverse music browsing needs. Derived from research that investigated how people use music in their everyday life (e.g., [67]), taxonomies such as mood and activity are being used.

Although, providing different taxonomies serve different browsing needs of users, taxonomies can start to compete with each other and thereby influence the overall satisfaction [47]. Even taxonomies that are not relevant for the search goal can distract the user [74], complicate the search process [9], and increase the search effort because of conflicting attention [54]. Therefore, understanding taxonomy preferences on an individual level is important to provide a personalized music experience. For example, music streaming services could emphasize the taxonomy that is important to the user while muting less preferred taxonomies to the background, or not showing them at all.

The subsequent amount of content within a taxonomy can further influence the users' preference strength and satisfaction with the eventually chosen item [53]. Ample research has shown that presenting more options may not always have positive effects. More options can cause overchoice (also referred as "choice overload"), which in turn influences the difficulty to make a choice and satisfaction with the eventually chosen item and decreases choice satisfaction $[6,46,51,80,86,88]$.

In this work we look at the two aforementioned aspects (i.e., taxonomic music browsing strategies and overchoice effect within taxonomies). To investigate taxonomic music browsing strategies, we explore the relation with personality traits. Personality has shown to be a reliable predictor of human preferences. It has shown to be an enduring factor that influences people's behavior [56], interests, and taste [32, 59, 78]. Hence, the preference for a certain taxonomic music browsing style may be reflected through users' personality as well. Furthermore, we look at the amount of content presented within a taxonomy on the occurrence of overchoice. As the effect of overchoice has been shown to be influenced by different moderators (e.g., expertise, choice set attractiveness. For an overview see Scheibehenne et al. [85]), we investigate whether the musical expertise of users influence the preference for a smaller or larger choice set. In this study, where we rely on stable constructs, such as personality and expertise, systems can be adapted towards specific behaviors, preferences, and needs of users. Hence, it allows systems to accommodate for a better user experience.

The research questions (RQs) that we try to answer in this work are:

RQ 1: How do personality traits relate to taxonomy (mood, activity, genre) preferences in music streaming services?

RQ 2: How does the size of the choice set influence the user experience (i.e., choice satisfaction, perceived system usefulness, and perceived system quality), and how is this moderated by expertise?

To investigate these research questions, we conducted a user study (preceded by a preliminary study) in which we simulated a music streaming service application. Among 297 participants we found that personality is related to different music browsing strategies. Furthermore, looking at the effect of the choice set size within a chosen music taxonomy, we found that musical expertise plays a moderating role in how the system is evaluated by the user. Within the mood taxonomy, participants with higher musical expertise rated the system 
as more useful and of higher quality when they were facing the choice set with less options. However, this was the other way around for the genre taxonomy, where participants with a higher music expertise rated the system more useful and of a higher quality when facing a bigger choice set. The presented findings have important implications on how music interfaces should be designed in order to maximize the user experience by facilitating in specific music preferences and needs of users. Based on our work, music services could be further personalized by adapting the user interface depending on the user's personality and level of music expertise. This allows for counteracting on decreased user experience by the user interface.

Overall, we provide new insights on how music streaming services can adapt their interfaces by targeting the user browsing needs, hence supporting users in finding music that they would like to listen to. Next to that, our work makes contributions to several research fields. Firstly, we contribute to the field of personality-based preferences. We show that personality does not only explain music genre preferences [78], but that it extends to the overarching music categorizations (i.e., taxonomies) by showing that personality traits are related to different music browsing strategies (i.e., browsing for music by mood, activity, or genre). Secondly, we contribute to the decision-making literature by extending the knowledge about when and how overchoice occurs in the context of music. For this we look at the categories within a taxonomy, and show that music expertise is an important influencing factor on the evaluation of the system and chosen item.

We investigated two different RQs within one study. Therefore, the remainder of the paper is structured as follows. We first discuss the related work separately for each RQ in Section 2. After the related work, we continue with the materials (Section 3) that were used for the user study to answer RQ 1 and 2. In Section 4 we discuss the preliminary study that was necessary to define the content for the user study. Subsequently, we divided Section 5 into Study A and B, where we will treat the hypotheses, findings, and discussion related to RQ 1 and 2. We discuss the limitations and future work in Section 6. Finally we round off the paper by drawing conclusions in Section 7 .

\section{Related work}

We review the literature about taxonomies and categories according to the two parts of our user study respectively. The first part discusses work that is related to the taxonomies and personality traits (Study A. Section 2.1), and the second part focuses on the overchoice effect (Study B. Section 2.2).

\subsection{Study A - taxonomies}

In the following sections we discuss how taxonomies influences users' decision making, and how personality is able to predict the preference for a taxonomy.

\subsubsection{Taxonomic influence}

The effects of overchoice have been well studied. However, most research on overchoice in consumer decision making has investigated choice satisfaction by focusing on choices in isolation (i.e., choices within a taxonomy; e.g., [6, 46, 51, 80, 86, 88]). For example, Iyengar and Lepper [51] investigated overchoice by using an assortment of on a specific set of jams, whereas Bollen et al. [6] created movie recommendations by using only the Top-5 and 
Top-20 movies. Although they found effects of overchoice on choices in isolation, others have shown that the satisfaction with the eventually chosen item already starts at the overarching categorizations; the taxonomies (e.g., [43, 47, 74]). Herpen et al. [47] asked their participants to choose a shirt from clothing brochures and found that taxonomies can distract in the decision making process. Their participants experienced higher decision effort, had more difficulties grasping the selection, andothing taxonomies (e.g., shirts, pants, shoes) than when substituted with content of one taxonomy (i.e., only shirts). Complementary taxonomies can cause consumers to extend their decision making time even when complementary taxonomies are not relevant for the initial search goal [74]. When taxonomies are placed next to each other, they start to compete and this is exacerbated especially when they consist of features that are unique and not directly comparable [43].

Although different taxonomies in music streaming services serve the same goal of providing users with music that they would want to listen to, they also consist of unique features that are not directly comparable: the taxonomies provide users the possibility to browse for music in different ways. In general, the mood taxonomy provides users with music that is similar to how they feel, the activity taxonomy provides music that fits a specific activity, and the genre taxonomy has music categorized based on a set of stylistic criteria. Given that the features of the taxonomies are not directly comparable, they can distract the user and increase the effort of picking the right music taxonomy to continue the music browsing. In the end, it can influence the satisfaction with the eventually chosen music item.

To minimize the negative influence of competing taxonomies, we try to counteract that by identifying the intrinsic music browsing preference of the user. By identifying the user's most preferable music browsing strategy, the system can anticipate the desired user interface. For example, the system can display the preferred music browsing taxonomy or already recommend music that is in line with a user's music browsing strategy (e.g., [26]). In order to identify the music browsing preference of users, we rely on personality traits. We will discuss prior work related to personality in the next section.

\subsubsection{Personality}

Personality has shown to be an enduring factor that influences an individual's behavior [56], interest, and tastes [59, 78]. As personality plays such a prominent role in shaping human preferences, one can expect similar patterns (i.e., behavior, interest, and tastes) to emerge between similar personality traits [10]. Different models have been created to categorize personality, where the five-factor model (FFM) is the most well known and widely used [69]. The FFM consists of five general dimensions that describe personality. Each of the five dimensions consist of clusters of correlated primary factors. Table 1 shows the general dimensions with the corresponding primary factors.

Table 1 The five-factor model adapted from McCrae and John [69]

\begin{tabular}{ll}
\hline General dimensions & Primary factors \\
\hline Openness to experience & Artistic, curious, imaginative, insightful, original, wide interest \\
Conscientiousness & Efficient, organized, planful, reliable, responsible, thorough \\
Extraversion & Active, assertive, energetic, enthusiastic, outgoing, talkative \\
Agreeableness & Appreciative, forgiving, generous, kind, sympathetic, trusting \\
Neuroticism & Anxious, self-pitying, tense, touchy, unstable, worrying \\
\hline
\end{tabular}


There is a growing amount of psychological literature investigating the relationship between personality traits and music consumption (e.g., [32, 38, 39, 76, 78, 79, 94]). For example, music preferences were found to be correlated with personality traits. Rentfrow and Gosling [78] categorized music pieces into four music-preference dimensions (reflective and complex, intense and rebellious, upbeat and conventional, and energetic and rhythmic), and found correlations with the five general personality dimensions (i.e., openness to experience, conscientiousness, extraversion, agreeableness, and neuroticism), such as, a relationship between energetic and rhythmic music, and extraversion and agreeableness. The psychological work on personality provides valuable information for the development of domain specific recommender systems.

Personality in personalized systems There has been an emergent interest in how to use personality in personalized systems (e.g., recommender systems), and several directions have been proposed (e.g., [14, 21, 23, 24, 26, 28, 34, 92, 93]). For example, Tkalcic et al. [93] propose a method to overcome the "cold-start problem" by including personality information to enhance the neighborhood measurement. $\mathrm{Hu}$ and $\mathrm{Pu}$ [49] have shown that personality-based recommender systems are more effective in increasing users' loyalty towards the system and decreasing cognitive effort compared to systems that do not use personality information.

\subsection{Study B - categories}

In this work, we further look into the influence of the number of categories presented within each taxonomy (Section 5.3). With this we join decision-making research on overchoice. Overchoice (or choice overload) refers to the increase of choice difficulty and eventual decrease of satisfaction as the number of choices increase. Iyengar and Lepper [51] were one of the first to define overchoice by testing the attractiveness between a set of 6 or 24 types of jam. Although their result shows that initially participants were more attracted to the larger (24 item) set, those who were exposed to the smaller (6 item) set were more inclined to actually buy a pot of jam (3\% and $30 \%$ respectively of the participants bought jam). Additionally, assessment of satisfaction showed that those who bought jam from the larger choice set were less satisfied compared to those with a purchase from the smaller choice set.

The overchoice effect has been replicated numerous times in different context, and was shown to affect motivation to choose as well as satisfaction with the chosen item (e.g., [6, $46,52,80,88])$. Shah and Wolford [88] found a motivational buying decrease in purchasing black pens when the assortment size increases. When they increased the assortment size of the black pens, participants' motivation to purchase decreased from $70 \%$ to $33 \%$. Reutskaja and Hogarth [80] investigated overchoice in the context of gift-boxes prices, and found that satisfaction with the chosen gift-box decreased when the number of gift-boxes to choose from increased. Similar findings were shown by Haynes [46] in the context of the number of lottery prices to choose from. Likewise, Bollen et al. [6] demonstrated a decrease in choice satisfaction in a movie recommender system among an increased number of movies to choose from.

Although there is an increased chance of a decrease in choice satisfaction, people somehow still cherish more choice, and studies have shown that shops with a large variety of

\footnotetext{
${ }^{1}$ The cold-start problem is most prevalent in recommender systems, and occurs when there is not enough data (yet) to recommend personalized items to the user. This problem especially occurs for new users.
} 
products even create a competitive advantage by providing more choices (e.g., $[1,8,12$, $13,50,57,63,68,72])$. So it seems that even though consumers risk to be more dissatisfied with their choice at the end, they still are attracted to more choices. A larger choice set becomes more attractive because of the summed benefit of each option, and thereby the total benefit of the set increases [18]. However, satisfaction decreases because making the right choice becomes more difficult. The psychological cost increases as a consequence of an increased number of choices. In other words, the summed benefit of a larger choice set is outweighed by the cost of comparing each option in order to make the right decision, increased risk of making a wrong choice, and increased expectations with the chosen item $[18,86,87]$. This results in that a larger choice set has a higher chance of decreased satisfaction or that no choice is made at all. Reutskaja and Hogarth [80] showed that overchoice occurs in an inverted satisfaction U-curve, where at one point the total cost of the choice set grows faster than the total benefit, causing a decrease of satisfaction.

Apart from studies that have shown the overchoice effect, there are also studies that demonstrate an opposing view (e.g., [5, 7, 19, 58, 91, 95]). They found that reducing the variety in retail shops often result in decrease sales or no change at all. Scheibehenne et al. [85] performed a meta-analysis of 50 studies voting against and in favor of the overchoice hypothesis, and found that the overall effect size comes close to zero. There seem to be necessary preconditions for a choice set before overchoice occurs [84, 85]. One factor is the attractiveness of the choice set plays. When items of a choice set are comparably attractive, and especially when they additionally consist of incomparable features, the chances of overchoice increases $[15,22]$. Furthermore, a factor that has shown to play a significant role is domain expertise $[70,85,96]$. Domain experts are less prone to be overwhelmed by the increasing number of choices, and therefore, overchoice is less likely to occur.

In order to investigate the overchoice within a music taxonomy, we first needed to create a choice set that meets the precondition (i.e., a choice set with attractive items). We conducted a preliminary study where we identified the categories that would be most attractive to our participants (see Section 4). Additionally, the moderator effect of musical expertise on overchoice is further investigated in Section 5.3.

\section{Method}

To investigate music taxonomy preferences for music browsing, and overchoice of categories within a music taxonomy, we created an online experiment where we simulated a music streaming service application. This application allowed us to study both RQ1

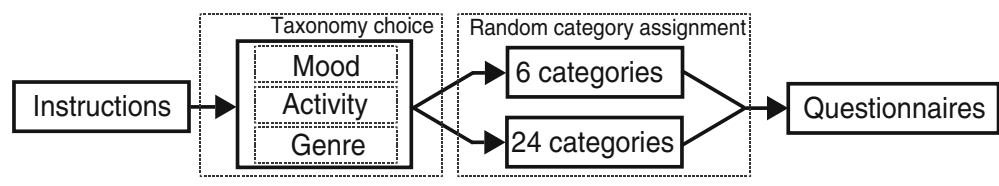

Fig. 1 Experiment work-flow. Participants were given instructions about the study, then continued by interacting with the music streaming application (see Section 5.2 for details). After choosing a music taxonomy to continue the music browsing, participants were randomly assigned to either the small choice set (i.e., 6-categories) condition or the large choice set (i.e., 24-categories) condition. After picking a category, participants continued to the concluding questionnaires 


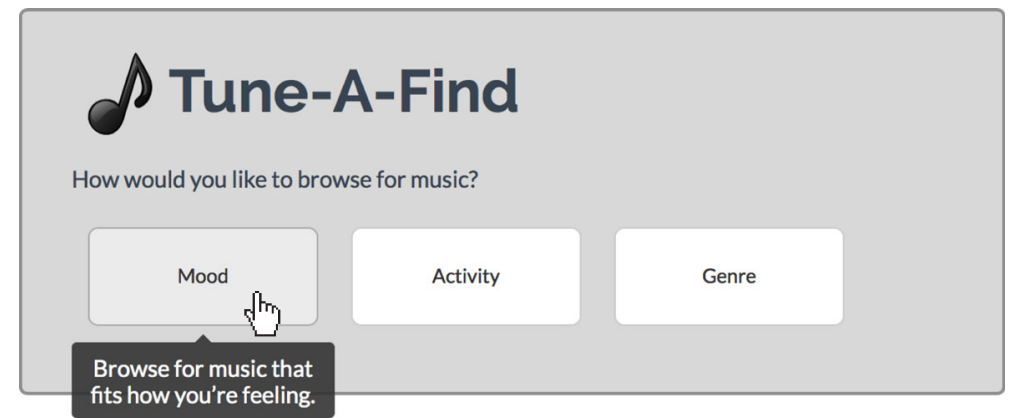

Fig. 2 Screen shot of Tune-A-Find with the "Mood" tooltip

and RQ2 at the same time. The studies are divided in Study A and Study B respectively. In the following sections we will discuss the experiment and the materials used in detail.

\subsection{Procedure}

To answer RQ1 and RQ2, we simulated a music streaming service application named "TuneA-Find" (see Fig. 1 for the work-flow of the experiment). Before participants started the experiment, instructions were given stating that they were about to test a new music streaming service. We emphasized that it is important that they interact with the application in the most ideal way for them. This allowed us to minimize experience bias with any of the taxonomies. After participants agreed with the instructions they continued by interacting with Tune-A-Find.

Tune-A-Find consists of a simple interface with three taxonomies (i.e., mood, activity, and genre) for participants to browse for music (see Fig. 2 and Section 5.2). A tooltip provided users a description of each taxonomy. ${ }^{2}$ The order of the taxonomies was randomized to prevent order effects. After participants chose a taxonomy to search music by (i.e., mood, activity, or genre), they continued on by choosing a category (i.e., type of mood, type of activity, or type of genre) within the chosen taxonomy.

For the categories within a chosen taxonomy, participants were randomly assigned to either the small choice set (i.e., 6-categories) condition or the large choice set (i.e., 24categories) condition (Fig. 3 and Section 5.3). The categories within each taxonomy were based on the results of the preliminary study (Section 4). We did not allow participants to go back to pick a different taxonomy. Therefore, we included a "None of the items" option. Category order was randomized with "None of the items" option always placed last to increase chances that participants would naturally assess all the options first. After participants picked a category, they continued with the concluding questionnaires (i.e., user experience, musical expertise, personality, and demographics questionnaires). We tried to maximize ecological validity by not including real music recommendations (so that evaluations of participants were not influenced by the algorithm) and by stressing out that the application concerned a prototype of a new music streaming service.

\footnotetext{
${ }^{2}$ Mood tooltip description "Browse for music that fits how you're feeling". Activity tooltip description "Browse for music that fits what you're doing". Genre tooltip description "Browse for music by music style".
} 

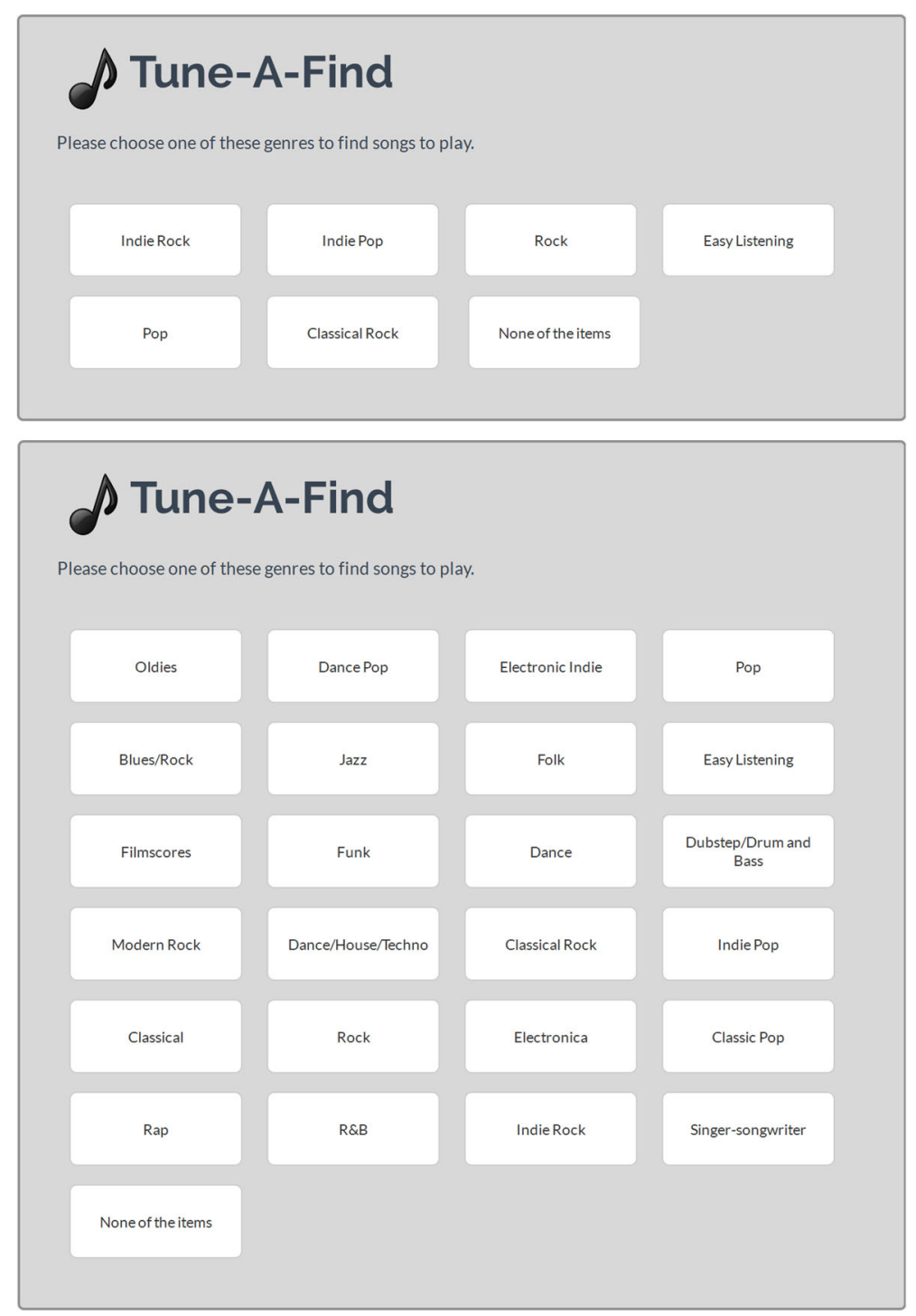

Fig. 3 Screen shots of the 6- and 24-categories conditions (top and bottom, respectively) with an extra option of "None of the items"

\subsection{Materials}

The taxonomies used in Tune-A-Find (i.e., mood, activity, and genre), are based on a close observation of current music streaming services. We found that these labels are increasingly being used (see Table 2).

For the number of categories to present within each taxonomy, we followed the original work of Iyengar and Lepper [51] on overchoice. They observed the occurrence of overchoice between choice sets consisting of 6 and 24-items. We conducted a separate user study to 
Table 2 Grasp of the observed music streaming services and the taxonomies they use to organize music

\begin{tabular}{llll}
\hline & Mood & Activity & Genre \\
\hline 8Tracks & $\mathrm{X}$ & $\mathrm{X}$ & $\mathrm{X}$ \\
AccuRadio & & $\mathrm{X}$ & $\mathrm{X}$ \\
Earbits & & $\mathrm{X}$ \\
Grooveshark & & $\mathrm{X}$ \\
Google Play Music & & & $\mathrm{X}$ \\
Guvera & & $\mathrm{X}$ & $\mathrm{X}$ \\
Jango & $\mathrm{X}$ & $\mathrm{X}$ \\
Last.fm & & $\mathrm{X}$ \\
Musicovery & $\mathrm{X}$ & $\mathrm{X}$ & $\mathrm{X}$ \\
Pandora & & & $\mathrm{X}$ \\
Slacker & & $\mathrm{X}$ & $\mathrm{X}$ \\
Songza & $\mathrm{X}$ & $\mathrm{X}$ & $\mathrm{X}$ \\
Spotify & $\mathrm{X}$ & $\mathrm{X}$ & $\mathrm{X}$ \\
\hline
\end{tabular}

determine which categorical labels (types of moods, activities, or genres) to include within each taxonomy (see Section 4).

For the concluding questionnaires we made use of existing questionnaires measuring: user experience, musical expertise, and personality. To measure user experience factors we adapted the original user experience questionnaire of Knijnenburg et al. [61] to fit the music streaming context of our study. The questionnaire depicts different parts of the user experience. It measures participants choice difficulty, choice satisfaction, perceived system usefulness, and perceived system quality. ${ }^{3}$

To measure participants' musical expertise, we relied on the Goldsmiths Musical Sophistication Index (Gold-MSI; [71]). Although recent research has shown that personality traits can predict music sophistication [25, 44], we decided to explicitly measure music sophistication in order to obtain a more accurate music sophistication measurement. The Gold-MSI questionnaire measures music sophistication based on the following dimensions:

- Active engagement (how much time and money one spends on music)

- Perceptual abilities (cognitive musical ability related to music listening skills)

- Musical training (musical training and practice)

- Signing abilities (skills and activities related to singing)

- Emotions (active behaviors related to emotional responses to music)

In the remainder of this paper, we will talk about "dimension expertise" to refer to the separate dimensions of the Gold-MSI. For this study we adopted parts of GoldMSI that are related to the taxonomies (i.e., active engagement, perceptual abilities, and emotions). ${ }^{4}$

To measure personality, we relied on the widely used, 44-item Big Five Inventory (5point Likert scale; disagree strongly - agree strongly; [55]). Finally, standard demographic questions were asked (i.e., age and gender).

\footnotetext{
${ }^{3}$ See Appendix B for the questions

${ }^{4}$ See also Appendix $\mathrm{C}$ for the used questions
} 


\section{Preliminary study}

To determine which categories to use in each taxonomy, we conducted a preliminary study. Prior research has shown that before overchoice occurs, the items in the choice set are subject to preconditions. For example, when the differences between the attractiveness of the items is small, and especially when they consist of incomparable features [15, 22].

In the following sections we outline the method and findings.

\subsection{Method}

For this preliminary study we recruited 45 participants through Amazon Mechanical Turk, a popular recruitment tool for user-experiments [60]. Only those located in the United States, and with a very good reputation were allowed to participate ( $\geq 95 \%$ Human Intelligence Task $[\mathrm{HIT}]^{5}$ approval rate and $\geq 1000$ HITs approved). We compensated participants with $\$ 1$ for their participation.

We extracted the categories provided by Songza, ${ }^{6}$ as they have a clear separation of categories between taxonomies whereas others (e.g., Spotify) have a mixed taxonomy view. For each taxonomy we asked participants to pick 12 categories $^{7}$ that they would most likely use when browsing for music.

\subsection{Findings \& conclusion}

In line with prior work of [51] on overchoice, and work defining the preconditions of the choice set $[15,22]$, we picked the 6 and 24 most attractive (i.e., the categories that participants indicated to use most likely in their music browsing) categories (Table 3), and were used for Study B (see Section 5.3) where we investigate overchoice within a music taxonomy.

\section{Main studies}

In the following subsections, we discuss the main studies where we treat the hypotheses, findings, and discussion for each study separately. Study A depicts the taxonomy preferences (Section 5.2), and Study B addresses the overchoice effect within a chosen taxonomy (Section 5.3). ${ }^{8}$

\subsection{Participants}

We recruited 326 participants through Amazon Mechanical Turk. Participation was restricted to those located in the United States, and also to those with very good reputation ( $\geq 95 \%$ HIT approval rate and $\geq 1000$ HITs approved) to avoid careless contributions. Participants were recruited at various times of the day to balance night and day time music application usage. Several comprehension-testing questions were used to filter out fake and

\footnotetext{
${ }^{5}$ Human Intelligence Tasks represent the assignments a user has participated in on Amazon Mechanical Turk prior to this study.

${ }^{6}$ see Appendix A for the complete surveyed list

${ }^{7} \mathrm{We}$ chose the arbitrary number of 12 as we believed that this would provide us with sufficient information without burdening the participants too much with answering.

${ }^{8}$ The studies extend the preliminary results published in Ferwerda et al. [33].
} 
Table 3 Top 6- and 24-categories chosen by participants. \# represents the number of votes

\begin{tabular}{|c|c|c|c|c|c|c|}
\hline & Mood & $\#$ & Activity & \# & Genre & $\#$ \\
\hline 1 & Energetic & 40 & Relaxing & 30 & Pop & 29 \\
\hline 2 & Happy & 37 & Being Creative & 26 & Rock & 23 \\
\hline 3 & Soothing & 35 & Rainy day & 24 & $\begin{array}{l}\text { Rock: Classic Alternative } \\
\text { \&Punk }\end{array}$ & 21 \\
\hline 4 & Mellow & 34 & Staying Up All Night & 22 & Indie: Indie Rock & 20 \\
\hline 5 & Atmospheric & 31 & Road Trip & 21 & Indie: Indie Pop & 19 \\
\hline 6 & Hypnotic & 30 & Working/Studying (without lyrics) & 19 & Easy Listening & 19 \\
\hline 7 & Introspective & 28 & Reading in a Coffee Shop & 18 & Classical & 18 \\
\hline 8 & Warm & 27 & Singing in the Shower & 18 & Blues \& Blues Rock & 18 \\
\hline 9 & Motivational & 27 & Housework & 18 & Film scores & 18 \\
\hline 10 & Funky & 25 & Working/Studying (with lyrics) & 17 & Folk & 17 \\
\hline 11 & Sad & 24 & Romantic Evening & 17 & Dance & 16 \\
\hline 12 & Celebratory & 24 & Gaming & 17 & $R \& B$ & 16 \\
\hline 13 & Nocturnal & 23 & Energy Boost & 17 & Pop: Classic Pop & 15 \\
\hline 14 & Aggressive & 22 & Working Out: Weight Training & 17 & Rap & 15 \\
\hline 15 & Seductive & 22 & Unwinding After Work & 16 & Oldies & 14 \\
\hline 16 & Gloomy & 22 & Working Out: Cardio & 16 & Electronica & 14 \\
\hline 17 & Sweet & 22 & Dance Party: Beach & 16 & Jazz & 14 \\
\hline 18 & Classy & 20 & House Party & 16 & Rock: Modern Rock & 13 \\
\hline 19 & Sexual & 19 & Barbecuing & 15 & Indie: Indie Electronic & 13 \\
\hline 20 & Raw & 19 & Lying Low on the Weekend & 15 & Dance: House \& Techno & 13 \\
\hline 21 & Angsty & 18 & Sleeping & 14 & Singer-Songwriter & 13 \\
\hline 22 & Visceral & 18 & City Cruising & 14 & Pop: Dance pop & 12 \\
\hline 23 & Spacey & 16 & $\begin{array}{l}\text { Waking Up on the Right Side } \\
\text { of the Bed }\end{array}$ & 12 & Funk & 12 \\
\hline 24 & Trippy & 16 & Lying on a Beach & 12 & Dubstep \& Drum 'n Bass & 12 \\
\hline
\end{tabular}

careless entries. This left us with 297 completed and valid responses. Age (19 to 68, with a median of 31) and gender (159 males and 138 females) information indicated an adequate distribution. Participants were compensated with $\$ 2$ for their participation.

\subsection{Study A}

In Study A, we looked at how taxonomy preferences are related to different personality traits. To investigate this relation we simulated a music streaming service (Fig. 2). The application consists of a simple interface with three taxonomies (mood, activity, and genre) for participants to browse for music. A tooltip provided users a description of each taxonomy. The order of the taxonomies was randomized to prevent order effects. Once a taxonomy was picked, participants continued by choosing a category within the chosen taxonomy (this is addressed in Study B in Section 5.3). As we are interested in users' intrinsic taxonomy preferences, participants were not able to go back once a taxonomy was picked. For those who want to choose a different taxonomy, we included an additional option of "None of the items" among the available categories. For those who picked this option, we included an additional question in the concluding questionnaire where they could indicate what they 
would have picked otherwise in terms of taxonomy (i.e., mood, activity, or genre) as well as the category within a taxonomy.

In order to prevent an experience bias with one of the music taxonomies (i.e., mood, activity, or genre), participants were told during the instructions of the user study that they were going to test a new music streaming service, and therefore it is important that they interact with the system in the most ideal way for them.

As there is no strong evidence from the literature to form hypotheses, we decided to adopt an exploratory approach. We try to draw relationships between our findings to what is known from prior research in the discussion section.

\subsubsection{Findings}

Using a chi-square test of independence, we explored the relationship between participants' five personality dimensions and the chosen music taxonomy (mood, activity, and genre). We used a median split to divide each personality trait into a low and high measure and a binary value was assigned to each taxonomy representing whether or not a participant chose for a certain taxonomy. The distribution of the music taxonomy choices made by the participants are shown in Table 5. Participants in general chose the genre taxonomy followed by the mood and activity taxonomies. In the following sections we discuss the relationship between personality traits and the music taxonomy chosen by the participants (see Table 4 for an overview).

Mood taxonomy Results of the chi-square test indicated a positive relationship between openness to experience and $\operatorname{mood} \chi^{2}(1, N=297)=3.117, p=.05$. This means that those who scored high on the openness to experience dimension were more likely to choose for mood than for activity or genre taxonomy. We did not find any significant effects of the other personality traits: conscientiousness $\chi^{2}(1, N=297)=.934, p=.334$, extraversion $\chi^{2}(1, N=297)=.870, p=.351$, agreeableness $\chi^{2}(1, N=297)=.044, p=.833$, and neuroticism $\chi^{2}(1, N=297)=.703, p=.402$.

Activity taxonomy When looking at the chi-square test results for the activity taxonomy, we found a positive significant effect of conscientiousness $\chi^{2}(1, N=297)=3.210$, $p=.05$. Additionally, we found a positive relationship of neuroticism $\chi^{2}(1, N=297)=$ $12.663, p<.001$. These results indicate that those who scored high on neuroticism or conscientiousness were more likely to choose the activity taxonomy. We did not find significant effects for openness to experience $\chi^{2}(1, N=297)=.046, p=.830$, extraversion $\chi^{2}(1$, $N=297)=.507, p=.477$, and agreeableness $\chi^{2}(1, N=297)=.406, p=.524$.

Table 4 Summary of the results for each taxonomy (i.e., mood, activity, and genre) with each personality trait: (O)pennes to experience, (C)onscientiousness, (E)xtraversion, (A)greeableness, and (N)euroticism

\begin{tabular}{llllll}
\hline & \multicolumn{6}{l}{$\chi^{2}(p)$} & & & \\
\cline { 2 - 6 } & $\mathrm{O}$ & $\mathrm{C}$ & $\mathrm{E}$ & $\mathrm{A}$ & $\mathrm{N}$ \\
\hline Mood taxonomy & $\mathbf{3 . 1 1 7 ( \mathbf { 0 . 0 5 } )}$ & $0.934(0.334)$ & $0.870(0.351)$ & $0.044(0.833)$ & $0.703(0.402)$ \\
Activity taxonomy & $0.046(0.830)$ & $\mathbf{3 . 2 1 0}(\mathbf{0 . 0 5})$ & $0.507(0.477)$ & $0.406(0.524)$ & $\mathbf{1 2 . 6 6 3 ( < \mathbf { 0 . 0 0 1 } )}$ \\
Genre taxonomy & $3.079(0.11)$ & $0.000(0.997)$ & $1.506(0.220)$ & $0.266(0.606)$ & $\mathbf{6 . 5 8 3}(\mathbf{0 . 0 1})$ \\
\hline
\end{tabular}

Bold faced numbers indicate a significance level of $\leq 0.05$ 
Genre taxonomy The chi-square test results for the genre taxonomy indicated a positive significant effect of neuroticism $\chi^{2}(1, N=297)=6.583, p=.01$, which implies that those who scored high on neuroticism were more inclined to choose for genre than for the other taxonomies.. All the other personality traits were not significant: openness to experience $\chi^{2}(1, N=297)=3.079, p=.11$, conscientiousness $\chi^{2}(1, N=297)=0, p=.997$, extraversion $\chi^{2}(1, N=297)=1.506, p=.220$, and agreeableness $\chi^{2}(1, N=297)=$ $.266, p=.606$.

Additional finding Additionally, we looked for effects of gender and age. Controlling for gender and age did not result in any significant effects. However, as seen in Table 5, the distribution of gender is interesting and indicates some trends. The distribution of women is higher in mood and activity, while conversely for genre.

\subsubsection{Discussion}

In this study, we investigated whether music taxonomy (mood, activity, and genre) preferences can be inferred from personality traits. We found that there is a relationship between personality traits taxonomy preferences that are used by music streaming services. We visualized our findings in Fig. 4.

We found a positive relationship between openness to experience and the mood taxonomy. This indicated that those scoring high on openness to experience are likely to choose for music organized by mood. Knoll et al. [62] found that open individuals show reciprocal behavior towards emotional support. Those scoring high on openness to experience are more aware of, and more capable to judge their own emotions. Therefore, music can play a supportive role for them, and would find greater benefit from browsing for music by mood.

Furthermore, a positive relationship between conscientiousness and the activity taxonomy was found. In other words, highly conscientious people show an increased preference for activity, but not for genre. Conscientiousness refers to characteristics, such as, selfdiscipline. People that score high on the conscientiousness scale tend to be more plan- and goal-oriented, organized, and determined compared to those scoring low [10]. As conscientious people are more plan- and goal-oriented, they would benefit of taxonomies that consist of concrete music categories (e.g., activities) to support their plans and goals.

Lastly, we found relationships between neuroticism and the activity and genre taxonomy. This indicates that those scoring high on neuroticism are more likely to choose for activity or genre. The neuroticism dimension indicates emotional stability and personal adjustment. High scoring on neuroticism are those that frequently experience emotional distress and wide swings in emotions, while those scoring low on neuroticism tend to be calm, well adjusted, and not prone to extreme emotional reactions [10]. Additionally, those who are highly neurotic do not believe that emotions are malleable, but rather difficult to control and strong in their expressions [45]. As neurotic people do not consider emotions to be easily changed, they will not benefit much from the mood taxonomy, but more of the activity or genre taxonomies instead.

Table 5 Distribution of men and women across the music taxonomy preference

\begin{tabular}{llll}
\hline Category & \#Male (percentage) & \#Female (percentage) & \#Total \\
\hline Mood & $26(38 \%)$ & $42(62 \%)$ & 68 \\
Activity & $5(31 \%)$ & $11(69 \%)$ & 16 \\
Genre & $128(60 \%)$ & $85(40 \%)$ & 213 \\
\hline
\end{tabular}


Fig. 4 Visualization of our findings: (O)penness to experience, $(\mathrm{C})$ onscientiousness, (E)xtraversion, (A)greeableness, (N)euroticism

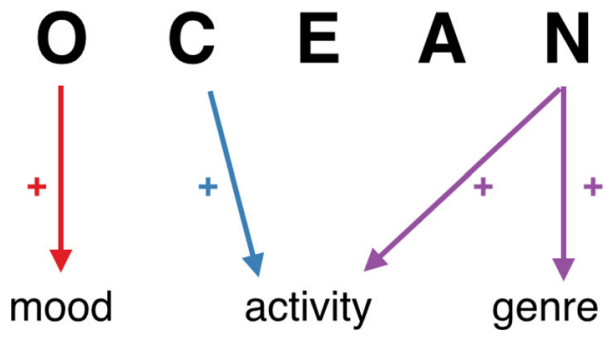

\subsection{Study B}

In Study B we looked into how the number of categories presented within a chosen music taxonomy influences the user experience (i.e., category choice satisfaction and difficulty, perceived system quality and usefulness), and how this effect is moderated by the participant's musical dimension expertise (i.e., active engagement, emotion, and perceptual abilities). The conditions (6- and 24-categories) of Study B originate from the behavior in Study A, where participants picked a music taxonomy to continue their music browsing (Study A; Section 5.2). In the following subsections we continue with hypotheses building, findings, and discussion.

\subsubsection{Hypotheses}

Overchoice is not always bound to occur; the choice set needs to satisfy preconditions. We covered the choice set preconditions in Section 4. However, overchoice does not only depend on choice set characteristics, but the user's characteristics play a role as well. A significant moderator for overchoice is the expertise of the user [11, 12, 64, 70, 85].

In line with findings showing expertise as a moderator for overchoice, we therefore hypothesize that also in the context of this study, expertise plays a role. In order to measure expertise, we rely on the different dimensions (i.e., active engagement, emotion, and perceptual abilities) of the Gold-MSI. The active engagement dimension depicts general music expertise (e.g., how much time and money one spends on music listening), while the dimensions emotion and perceptual abilities depict expertise related to the individual music taxonomies (mood and genre taxonomy respectively). For example, the emotion dimension is related to how often someone might choose music that will send shivers down their spine or how often music can evoke memories of past people and places, thereby mapping to the mood taxonomy. As the perceptual ability dimension is related to how well someone can compare two pieces of music or how well someone can identify genres of music, thereby mapping to the genre taxonomy. The active engagement dimension depicts general behavior, we believe that it has a positive effect in both the mood and genre music taxonomy.

Furthermore, we do not only investigate the effects of overchoice on choice satisfaction, but assess other parts of the user experience as well. Besides satisfaction, we also include choice difficulty, perceived system quality, and perceived system usefulness. Unless otherwise specified, we will refer to these factors as the user experience.

We hypothesize:

H1: The number of categories within any of the taxonomies will have a positive effect on the user experience for dimension experts in active engagement, but not for nonexperts. 
Table 6 Distribution of chosen categories within each taxonomy (6-categories condition)

\begin{tabular}{lllllll}
\hline & Mood & $\#$ & Activity & $\#$ & Genre & $\#$ \\
\hline 0 & None & 2 & None & 3 & None & 20 \\
1 & Energetic & 8 & Relaxing & 0 & Pop & 16 \\
2 & Happy & 6 & Being creative & 2 & Rock & 30 \\
3 & Soothing & 5 & Rainy day & 0 & Classical Rock & 21 \\
4 & Mellow & 10 & Staying up all night & 4 & Indie Rock & 11 \\
5 & Atmospheric & 3 & Road trip & 0 & Indie Pop & 2 \\
6 & Hypnotic & 2 & Working/studying & 3 & Easy Listening & 7 \\
& & & without lyrics & & & 107 \\
Total & & & & & & \\
\hline
\end{tabular}

The dimensions emotion and perceptual abilities are more specifically oriented towards the mood and genre music taxonomy. Therefore we hypothesize:

$\mathrm{H} 2$ : The number of categories within the mood taxonomy will have a positive effect on the user experience for dimension experts in emotion, but not for non-experts.

H3: The number of categories within the genre taxonomy will have a positive effect on the user experience for dimension experts in perceptual abilities, but not for non-experts.

We do not hypothesize overchoice within the activity taxonomy as it depicts specific activities, and is unrelated to any kind of expertise or ambiguity.

\subsubsection{Findings}

A multivariate analysis of variance (MANOVA) was conducted to test for user experience (i.e., perceived system usefulness, perceived system quality, choice difficulty, and choice satisfaction) differences between 6- and 24-categories. With the MANOVA we first tested differences between the number of categories within each music taxonomy (i.e., without controlling for expertise). Tables 6 and 7 show the categories that the participants chose, and the total distribution across the music taxonomies respectively. Results show that for the mood, activity, and genre taxonomies, participants did not experience any significant difference whether it was the smaller choice set or the bigger choice set that they chose from (see Table 8 for means and standard deviations).

In order to investigate the effects of expertise, we conducted a moderated multiple regression (MMR) analysis. We used the dimensions of the Gold-MSI (i.e., active engagement, perceptual abilities, and emotions) to assess participants' expertise level, and added these as a moderator to the analyses. This allowed us to investigate how expertise influences the overchoice effect and the user experience factors (i.e., perceived system usefulness, perceived system quality, choice difficulty, and choice satisfaction).

The analyses were conducted in two steps. ${ }^{9}$ In the first step we tested for main effects. This allowed us to see the general effects of expertise on the user experience factors within each music taxonomy, regardless of the number of categories. The second step involved the

${ }^{9}$ The full results can be found in Appendix D 
Table 7 Distribution of chosen categories within each taxonomy (24-categories condition)

\begin{tabular}{|c|c|c|c|c|c|c|}
\hline & Mood & $\#$ & Activity & \# & Genre & $\#$ \\
\hline 0 & None & 0 & None & 0 & None & 5 \\
\hline 1 & Energetic & 2 & Relaxing & 0 & Pop & 9 \\
\hline 2 & Happy & 4 & Being creative & 0 & Rock & 9 \\
\hline 3 & Soothing & 4 & Rainy day & 0 & Classical Rock & 8 \\
\hline 4 & Mellow & 3 & Staying up all night & 0 & Indie Rock & 5 \\
\hline 5 & Atmospheric & 1 & Road trip & 0 & Indie Pop & 2 \\
\hline 6 & Hypnotic & 0 & Working/studying without lyrics & 0 & Easy Listening & 4 \\
\hline 7 & Introspective & 1 & Reading in a coffee shop & 0 & Classical & 0 \\
\hline 8 & Warm & 1 & Singing in the shower & 0 & Blues/Rock & 3 \\
\hline 9 & Motivational & 1 & Housework & 2 & Film scores & 4 \\
\hline 10 & Funky & 1 & Working/studying with lyrics & 0 & Folk & 5 \\
\hline 11 & Sad & 1 & Romantic evening & 0 & Dance & 1 \\
\hline 12 & Celebratory & 0 & Gaming & 0 & $\mathrm{R} \& \mathrm{~B}$ & 6 \\
\hline 13 & Nocturnal & 1 & Energy boost & 0 & Classic Pop & 4 \\
\hline 14 & Aggressive & 0 & Working out: weight training & 0 & Rap & 6 \\
\hline 15 & Seductive & 1 & Unwinding after work & 0 & Oldies & 7 \\
\hline 16 & Gloomy & 1 & Working out: cardio & 2 & Electronica & 7 \\
\hline 17 & Sweet & 0 & Beach party & 0 & Jazz & 5 \\
\hline 18 & Classy & 2 & House party & 0 & Modern Rock & 8 \\
\hline 19 & Sexual & 3 & Barbequing & 0 & Electronic Indie & 2 \\
\hline 20 & Raw & 1 & Lying low on the weekend & 0 & Dance/House/Techno & 2 \\
\hline 21 & Angsty & 1 & Sleeping & 0 & Singer-songwriter & 1 \\
\hline 22 & Visceral & 1 & City cruising & 0 & Dance Pop & 1 \\
\hline 23 & Spacey & 2 & Waking up on the right side of the bed & 0 & Funk & 1 \\
\hline 24 & Trippy & 0 & Lying on a beach & 0 & Dubstep/Drum and Bass & 1 \\
\hline Total & & 32 & & 4 & & 106 \\
\hline
\end{tabular}

moderators (i.e., emotion, perceptual abilities, and active engagement dimension expertise). By including the moderators, we were able to look at how expertise influences overchoice, and in turn the user experience.

We separately discuss the significant findings of each music taxonomy on the user experience factors (i.e., perceived system usefulness, perceived system quality, choice difficulty, and choice satisfaction) below. In each of the following result sections, we first start with the

Table 8 Mean and standard deviations of the user experience factors on category size per taxonomy

\begin{tabular}{|c|c|c|c|c|c|c|}
\hline & \multicolumn{2}{|l|}{ Mood } & \multicolumn{2}{|l|}{ Activity } & \multicolumn{2}{|l|}{ Genre } \\
\hline & 6 & 24 & 6 & 24 & 6 & 24 \\
\hline Perceived system usefulness & $4.07(.78)$ & $4.14(.68)$ & $3.50(1.21)$ & $4.25(.50)$ & $3.71(.96)$ & $4.02(.88)$ \\
\hline Perceived system quality & $3.95(.84)$ & $4.10(.78)$ & $3.21(1.23)$ & $4.37(.48)$ & $3.50(1.26)$ & $4.01(1.09)$ \\
\hline Choice difficulty & $.97(.17)$ & $.94(.25)$ & $.83(.39)$ & $.75(.50)$ & $.90(.30)$ & $.91(.29)$ \\
\hline Choice satisfaction & $4.21(.72)$ & $4.27(.59)$ & $3.46(1.37)$ & $4.37(.63)$ & $3.91(1.08)$ & $4.31(.81)$ \\
\hline
\end{tabular}


significant main effects (i.e., the effect of expertise on the user experience without taking into account the different number of categories). After that we continue with the significant moderator effects (i.e., the effect of expertise on overchoice and the user experience).

Mood taxonomy When looking at the results of perceived system usefulness, we found a significant main effect of emotion expertise $(t(1,63)=1.939, p=0.05)$. This indicates that in general participants that are emotion experts found the system more useful than non-experts. For perceived system quality, we found a significant main effect of active engagement expertise $(t(1,63)=-2.379, p=0.02)$, as well as emotion expertise $(t(1,63)=2.285, p=0.02)$. This means that active engaged participants indicated that they perceived the system of lower quality while participations with emotion expertise rated the system of higher quality. Furthermore, we found a main effect on choice satisfaction of emotion expertise $(t(1,63)=1.764, p=0.08)$, indicating that those who use music for emotional activities are in general more satisfied with their category label choice.

When looking at differences between the number of categories while controlling for the expertise dimensions, we found the following moderator effects on the different factors of the user experience. For the perceived system usefulness, we found a significant moderator effect of emotion expertise $(t(1,63)=-2.147, p=0.03)$. The results of the moderator effect indicate that emotion experts perceived the system as less useful when given more choices, while non-emotion experts perceived the system as more useful when given more choices (Fig. 5). When looking at the perceived system quality, we found a moderator effect of emotion expertise $(t(1,63)=-1.834, p=0.07)$, indicating that emotion experts perceived the system of less quality when given more choices (Fig. 6). Lastly, we identified moderator effects on choice difficulty by emotion expertise and active engagement expertise. Emotion experts show a decrease in choice difficulty when given less choices $(t(1,63)=-1.754, p=0.08$; Fig. 7$)$, whereas active engagement experts show a decrease of choice difficulty when given more choices $(t(1,63)=2.385, p=0.02$; Fig. 8$)$. No significant effects were found on choice satisfaction.

Activity taxonomy As expected, no main or moderator effects were found for the categories within the activity taxonomy.

Genre taxonomy No main effects were found of the different expertise dimensions on the user experience. However, moderator effects were observed on the user experience factors

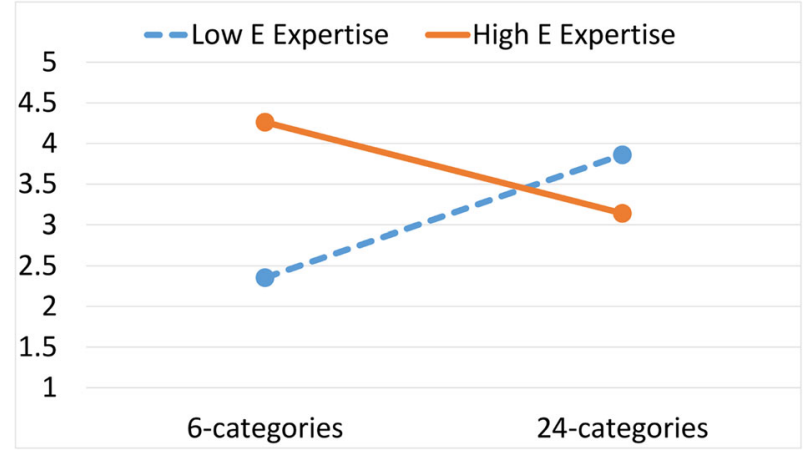

Fig. 5 Moderator effect of emotion (E) expertise on perceived system usefulness (higher means more useful) within the mood taxonomy 


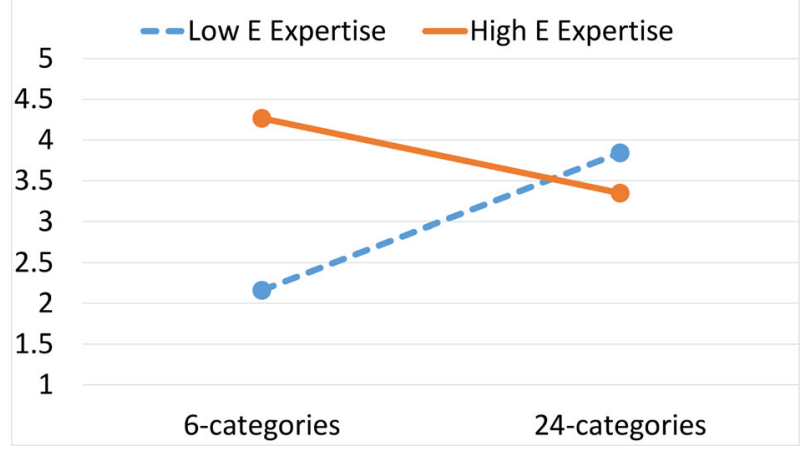

Fig. 6 Moderator effect of emotion (E) expertise on perceived system quality (higher means higher quality) within the mood taxonomy

when looking at the differences between the number of categories. A significant moderator effect was found on perceived system usefulness when controlling for perceptual abilities expertise $(t(1,197)=2.260, p=0.02)$. Participants with expertise in perceptual abilities rated the system as more useful when given more choices. On the other hand, those with low perceptual abilities rated the system as more useful when given less choices (Fig. 9). For perceived system quality, we found a moderator effect of perceptual abilities expertise $(t(1,197)=1.838, p=0.06)$. The results show that perceptual experts rated the system of higher quality when given more choices, while it hardly made a difference for non-experts (Fig. 10). No significant effects were found on choice satisfaction or choice difficulty by expertise in perceptual abilities, nor did we find any effects on the user experience factors by active engagement.

\subsubsection{Discussion}

Our results show that expertise plays a role in whether overchoice occurs or not. With regards to $\mathrm{H} 1$, we only found partial support. We hypothesized that general musical expertise (active engagement), would play a role in whether overchoice occurs. However, we only found an overchoice effect in the mood taxonomy on choice difficulty. Those who were more expert indicated to find it more difficult to choose a category when they were given

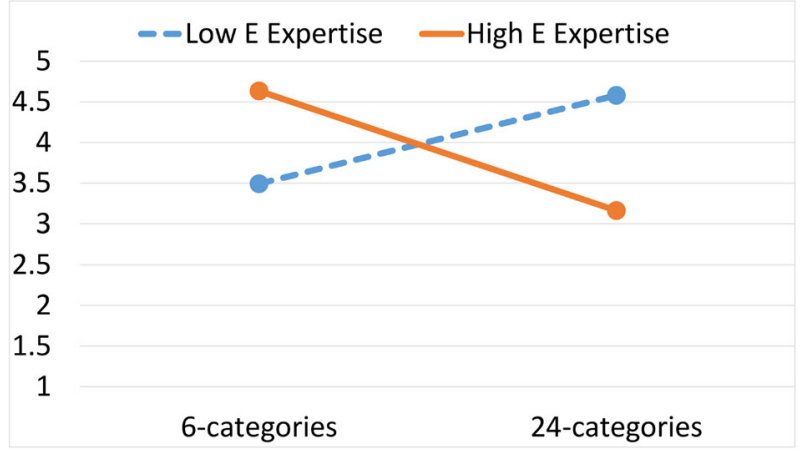

Fig. 7 Moderator effect of emotion (E) expertise on choice difficulty (higher means easier) within the mood taxonomy 


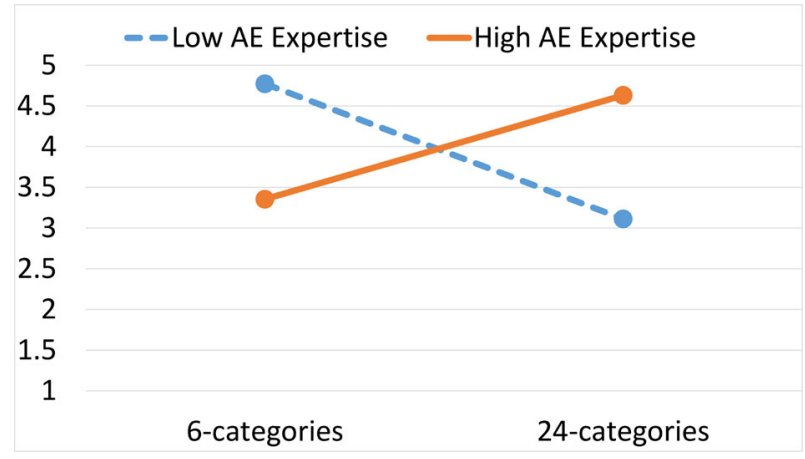

Fig. 8 Moderator effect of active engagement (AE) expertise on choice difficulty (higher means easier) within the mood taxonomy

less choice, whereas non-experts indicated to experience more difficulties when given more choice. As this was the only effect found, the effect of expertise seem to be very specific, and cannot take any general form.

Remarkable is the effect of emotion expertise within the mood taxonomy. Here, the emotion expertise seem to adopt an opposite effect of overchoice. Therefore, we need to reject our hypothesis (H2). Instead of an increase in the user experience factors when given more choice, emotion experts show a decrease. In other words, they perceived the system as more useful and of higher quality, and indicated to have less difficulties to pick a category, when provided less choice. Non-experts indicated the opposite effect and were experiencing a higher user experience when given more choices. A possible explanation for this could be that emotional experts are in general more emotionally aroused and therefore prefer less choice because it takes less cognitive effort. This is in line with findings that show that emotional arousal can have an adverse effect on decision making because of reduced cognitive processing $[20,66]$. In other words, information processing decreases as a result of emotional arousal. Making a choice from a bigger choice set would then take more effort to assess every option. Also, especially for those who rely more on the emotional triggers of music, making a bad choice will have bigger consequences than making a good choice [3]. Hence, as the choice sets within each music taxonomy were designed to be most attractive, choice difficulty within the mood taxonomy is exacerbated for the more experienced ones.

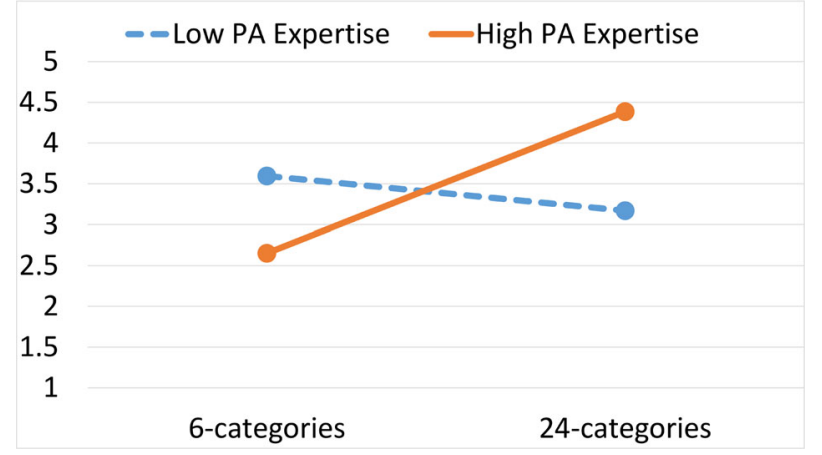

Fig. 9 Moderator effect of perceptual abilities (PA) expertise on perceived system usefulness (higher means more useful) within the genre taxonomy 


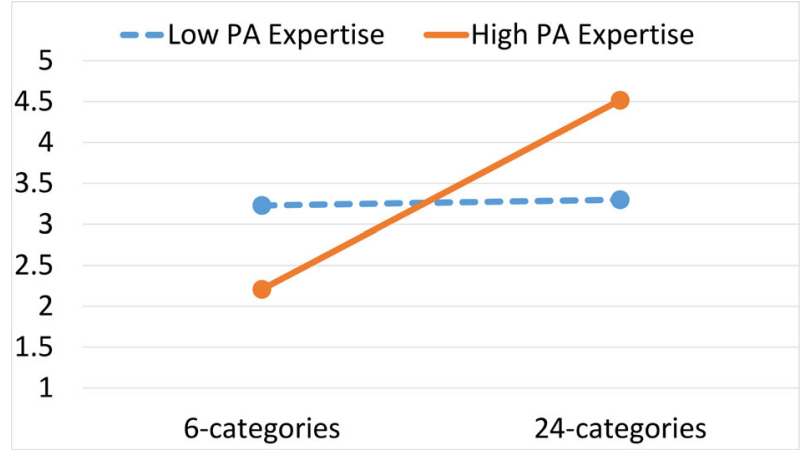

Fig. 10 Moderator effect of perceptual abilities (PA) expertise on perceived system quality (higher means higher quality) within the genre taxonomy

The effect of expertise in the genre taxonomy is partially in line with our hypothesis (H3). Prior research suggests that expertise is a moderator for overchoice $[11,12,64,70$, 85]. Those who indicated to be experts in perceptual abilities rated the system of higher quality, and more useful, when more choices were provided.

It is striking that we did not observe a clear overchoice effect on the choice that was made (i.e., choice difficulty and choice satisfaction), but only on the evaluation of the system (i.e., perceived system usefulness and perceived system quality). Evaluating the necessary preconditions for overchoice to occur state that the user needs to have a lack of familiarity with the items, and should not have a clear prior preference for an item [51]. However, not meeting these preconditions should lead to preferring more choice [11, 12], whereas our results show no differences. Others argue that overchoice can only occur when all options are attractive. So, there should be no dominant option and the proportion of non-dominant options should be large [16, 17, 48, 77]. Otherwise, making a decision would be easy, regardless of the size of the choice set. In this study, we tried to control for that by creating choice sets with the most attractive items (see the preliminary study in Section 4). Also, by looking at the distribution of the choices made by the participants (see Tables 6 and 7), there is no category that excessively stands out of being chosen. The most plausible explanation for why we did not observe the hypothesized effects comes from Hutchinson [50]. He argued that overchoice seldom occurs among animals, because they seem to have adapted to the different sizes of choice sets that naturally occur in their environment. Although this hypothesis has not been verified on humans so far, it would explain best why the overchoice effect on the choices made (i.e., choice difficulty and choice satisfaction) was not found in our study. The sizes of the choice sets we used are not uncommon for music streaming services. We picked the size of our largest choice set (24 categories) to be in line with the original work of overchoice by Iyengar and Lepper [51]. However, this was just a subset of what would be presented to actual users of such a service. It could be that participants are accustomed to the sizes of the presented choice sets as currently in music streaming services they would need to deal with even larger choice sets than used in this study.

Although we did not experience the overchoice effect on the category items, it does not mean that our choice sets did not have any effects. We did find effects on the factors evaluating the system (i.e., perceived system usefulness and perceived system quality). These are important factors that help to form users' general perspective of the system as a whole.

Aside of the fact that our results contribute to knowledge on how to design online music systems (see Section 5.4), our results also contribute to knowledge in other domains (see 
Fig. 11 for a visualization of our results). We show that personality traits relate to interactions within online music systems and thereby provide insights on how personality relate to online behaviors through new interactions methods that technologies are facilitating. Furthermore, our results provide additional insights important for decision making research by showing the versatility of expertise on the overchoice paradigm. Although expertise showed to be an important influencing factor, we show that it is case dependent whether it contributes to overcoming the overchoice effect.

\subsection{Implications}

The results of these studies support the creation of personalized user interfaces by taking into account the user's personality and expertise (a proposed user model can be found in Fig. 11). With applications getting more and more connected and sharing resources (e.g., applications connect with social networking sites, such as, Facebook, Twitter, or Instagram), the automatic extraction of personality and expertise becomes more available. A possible scenario could be:

A user has the music application connected to his Facebook account. Based on his Facebook profile, the application inferred that he is someone open to new experiences. Therefore, the music application adjusts the user interface by emphasizing the mood taxonomy to let the user continue browsing for music. By analyzing his profile (e.g., he filled in artists and bands that he likes) and postings (e.g., posting often that he goes to concerts), the system may infer that he is actively engaged with music. Based on this, the system decides to provide him more categories to choose from within the mood taxonomy.

In the last couple of years, it has been demonstrated that personality information can be extracted from social networking sites (SNSs) like Facebook (e.g., [2, 35, 42, 73, 81]), Twitter (e.g., [41, 75]), and Instagram (e.g., [29-31, 36, 65], or a combination of such [89]). Being able to extract personality traits from SNSs caters the possibility for (music) applications to adjust their user interface based on our results. For example, when someone appears to be open to new experiences, the mood taxonomy could be emphasized while other taxonomies could be placed more in the background of the interface. In addition,

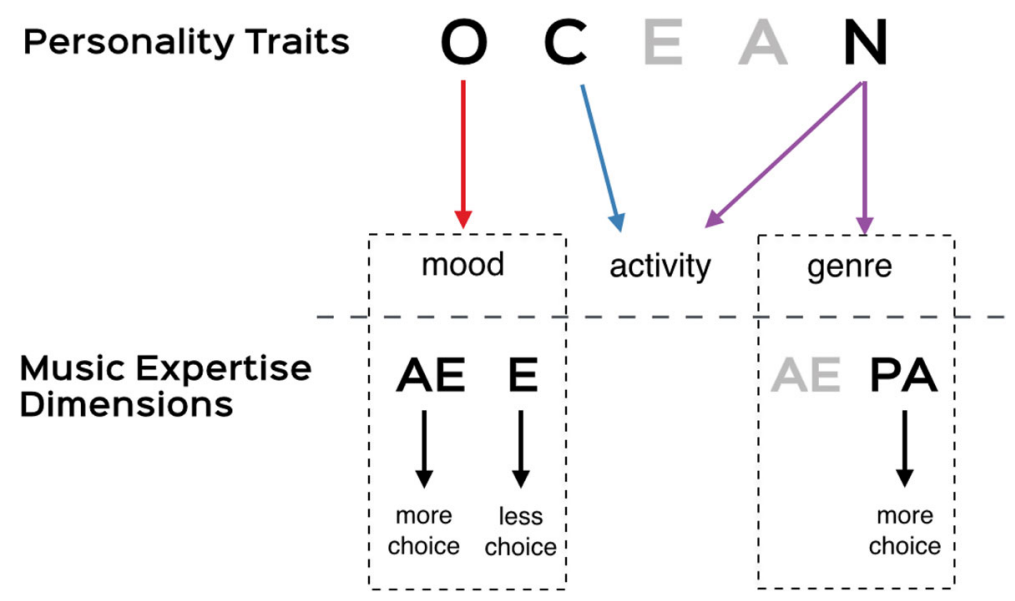

Fig. 11 Proposed user model. Personality traits: (O)penness to experience, $(\mathrm{C})$ onscientiousness, (E)xtraversion, (A)greeableness, (N)euroticism. Music expertise dimensions: active engagement (AE), perceptual abilities (PA), emotions (E) 
music recommendations could be given based on the mood taxonomy (e.g., music with similar mood expression).

Although recent work has shown that personality can predict music sophistication $[25,44]$, we believe that also the expertise dimensions (i.e., active engagement, perceptual abilities, and emotions) that we used in Study B, can be inferred from the same increased connectedness with SNSs. For example, active engagement can be inferred by extracting information on concert attendance (e.g., Facebook events, SongKick; http://www.songkick. com) as well as purchase behavior (e.g., iTunes store, Amazon; http://www.amazon.com). The "About" section, or the posted activities and status updates in SNSs can provide cues to infer perceptual abilities. Analyzing postings of a SNS user could give an indication about the emotion expertise dimension (e.g., postings about induced feelings when listening to a song). Also, there seems to be some relationship between factors of the emotion expertise dimension and the openness to experience personality factor. This could serve as an additional indicator. Music applications could anticipate the choice set based on the expertise dimension of the user.

\section{Limitations \& future work}

There are several limitations in this study that should be addressed in future work. Our sample focused only on participants situated in the United States. Recent work showed that there are cultural differences in music consumption (e.g., [27, 37, 82, 83, 90]). Hence, cultural differences may also play a role in taxonomy usage and category preferences. Future work should address this.

We tested the relationship between personality traits and independent music taxonomies (i.e., mood, activity, and genre). One of our results show a relationship between neuroticism and the activity and genre taxonomy. On the other hand, it could well be that people prefer combinations of taxonomies (e.g., sad pop music, funky road trip music, or happy cooking music).

In the studies we conducted, we intentionally did not include real music recommendations as we believed this could interfere with rightfully answering our research questions. Since this study only simulated the decision making stage of using a music streaming service and did not play any actual music, it may have limiting effects on the holistic user experience.

\section{Conclusion}

The goal of this work was to investigate whether music browsing strategies are related to personality traits, by looking at the decision making of picking a music taxonomy (mood, activity, or genre) to browse for music. Additionally, we looked at the occurrence of overchoice with the number of categories within the music taxonomies, and how this effect is moderated by expertise.

We found that users' choice of a taxonomy (mood, activity, or genre) to browse for music, is related to their personality. We found significant effects between openness to experience and the mood taxonomy, Conscientiousness and the activity taxonomy, neuroticism and the activity taxonomy, and neuroticism and the genre taxonomy. Furthermore, our results show that overchoice is moderated by expertise. We found that the effects of overchoice is counteracted by expertise in the genre taxonomy (i.e., a positive relationship between 
expertise and more choices). However, having more expertise/experience does not always make choosing easier. In our case, emotion experts (e.g., those who easily identify with emotions in music) had more difficulties making a decision with an increased choice set (i.e., a negative relationship with expertise). Although expertise may take the role as a proxy measure for cognitive processing, by assuming that expertise and experience with the topic makes processing information about the topic easier, this does not always seem true. In some cases, expertise or more experience can create averse effects.

Finally, while the majority of prior research focuses on the influence of overchoice on choice satisfaction and/or choice difficulty, we show with our results that overchoice does not necessarily limit its influence to these two factors. Our results show that even when choice satisfaction or difficulty are not affected by the overchoice effect, it may still influence other aspects of the user experience (e.g., system usefulness, and system quality). These other factors of the user experience should not be neglected, and could play an important role in the recurring use of the system by users.

Open Access This article is distributed under the terms of the Creative Commons Attribution 4.0 International License (http://creativecommons.org/licenses/by/4.0/), which permits unrestricted use, distribution, and reproduction in any medium, provided you give appropriate credit to the original author(s) and the source, provide a link to the Creative Commons license, and indicate if changes were made.

\section{Appendix A: Categories}

Music categories extracted from Songza (http://www.songza.com)

\begin{tabular}{llll}
\hline $\mathrm{Nr}$ & Mood & Activity & Genre \\
\hline 1 & Visceral & Housework & Blues \& Blues Rock \\
2 & Mellow & Drinking at a Dive Bart & Bluegrass \\
3 & Celebratory & Hanging Out in the Man Cave & Children's \\
4 & Warm & Road Trip & Christian \\
5 & Motivational & Skateboarding & Christian: Gospel \\
6 & Angsty & Working/Studying (without lyrics) & Christmas \\
7 & Trashy & Getting High & Classical \\
8 & Seductive & Going for a Bike Ride & Classical: Crossover \\
9 & Hypnotic & Unwinding After Work & Classical: Vocal \\
10 & Rowdy & Staying up all Night & Country \\
11 & Aggressive & Dance Party: Beach & Country: Contemporary \\
& & & Country \\
12 & Sweet & Singing in the Shower & Dance \\
13 & Soothing & Energy Boost & Dance: Disco \\
& & & \& Nu Disco \\
14 & Introspective & Slow Dancing & Dance: House \& Techno \\
15 & Raw & Sitting on a Back Porch & Dancehall \\
16 & Gloomy & Reading in a Coffee Shop & Dubstep \& Drum 'n Bass \\
17 & Atmospheric & Working Out: Cardio & Easy Listening \\
18 & Nocturnal & Breaking Up & Electronica \\
19 & Cold & Making Out & Film Scores \\
20 & Spacey & Dinner Party: Formal & Folk \\
21 & Earthy & Workout Cool Down & Funk \\
& & &
\end{tabular}




\begin{tabular}{|c|c|c|c|}
\hline 22 & Lush & Getting Lucky & Hawaiian \\
\hline 23 & Sexual & Driving in the Left Lane & Indie: Indie Electronic \\
\hline 24 & Classy & Working Out: Weight Training & $\begin{array}{l}\text { Indie: Indie Folk } \\
\text { \& Americana }\end{array}$ \\
\hline 25 & Trippy & Lying on a Beach & Indie: Indie Pop \\
\hline 26 & Energetic & House Party & Indie: Indie Rock \\
\hline 27 & Sprightly & Barbecuing & International/World \\
\hline 28 & Funky & Cocktail Party & International: African \\
\hline 29 & Campy & Romantic Evening & International: Asian \\
\hline 30 & Happy & Rainy Day & International: Brazilian \\
\hline 31 & Sad & $\begin{array}{l}\text { Waking Up on the } \\
\text { Right Side of the Bed }\end{array}$ & International: Jamaican \\
\hline 32 & Cocky & $\begin{array}{l}\text { Working/Studying } \\
\text { (with lyrics) }\end{array}$ & International: Mediterranean \\
\hline 33 & & Dance Party: Sweaty & Jazz \\
\hline 34 & & Lounging in a Cool Hotel & Jazz: Vocal Jazz \\
\hline 35 & & Lying Low on the Weekend & Latin \\
\hline 36 & & Yoga & Latin: Cuban \\
\hline 37 & & Pleasing Crowd & Latin: Puerto Rican \\
\hline 38 & & Coding & Latin: Salsa \\
\hline 39 & & Pool Party & Latin: Tropical \\
\hline 40 & & Sleeping & Nature Sounds \& Soundscapes \\
\hline 41 & & Dinner Party: Casual & Oldies \\
\hline 42 & & Gaming & Pop \\
\hline 43 & & Relaxing & Pop: Classic Pop \\
\hline 44 & & City Cruising & Pop: Dance Pop \\
\hline 45 & & Coming Down After a Party & Pop: Soft Pop \\
\hline 46 & & Stripping & $\mathrm{R} \& \mathrm{~B}$ \\
\hline 47 & & Shopping at a Vintage Store & R\&B: Classic R\&B \\
\hline 48 & & Ballroom Dancing & R\&B: Contemporary R\&B \\
\hline 49 & & Dirt Road Driving & R\&B: Soul \\
\hline 50 & & Walking Through a City & Rap \\
\hline 51 & & Dance Party: Fun \& Funky & Rap: Classic Mainstream Rap \\
\hline 52 & & Being Creative & Rap: Old School Rap \\
\hline 53 & & Cooking with Friends & Rap: Today’s Mainstream Rap \\
\hline 54 & & Girls Night Out & Rap: Underground \& Alternative Rap \\
\hline 55 & & Getting Married & Reggae \& Ska \\
\hline 56 & & Grinding at a Nightclub & Reggaeton \\
\hline 57 & & & Rock \\
\hline 58 & & & Rock: Classic Alternative \& Punk \\
\hline 59 & & & Rock: Contemporary Alternative \\
\hline 60 & & & Rock: Emo/Pop-Punk \\
\hline 61 & & & Rock: Hard Rock \\
\hline 62 & & & Rock: Metal \\
\hline 63 & & & Rock: Modern Rock \\
\hline 64 & & & Rock: Rockabilly \\
\hline 65 & & & Singer-Songwriter \\
\hline 66 & & & Showtunes \\
\hline
\end{tabular}




\section{Appendix B: User experience}

Below the questions depicting the user experience (adapted from [61]).

\section{B.1 Choice satisfaction}

5-point Likert scale: disagree strongly - agree strongly.

\section{$\mathrm{Nr}$ Question}

1 I don't like the item I chose (negated).

2 I am enthusiastic about the item I chose.

\section{B.2 Perceived choice difficulty}

5-point Likert scale: very difficult - very easy.

\section{Nr Question}

1 How difficult was it to choose an item from the list?

\section{B.3 Perceived system usefulness}

5-point Likert scale: disagree strongly - agree strongly.

\section{Nr Question}

1 With this way of finding music, I can make better choices.

2 I don't find this way of finding music useful (negated).

3 I would use this way of finding music more often if it was possible.

\section{B.4 Perceived system quality}

5-point Likert scale: disagree strongly - agree strongly.

\section{Nr Question}

1 I found good items in the list.

2 The list did not consist any of my preferred items (negated).

\section{Appendix C: Music sophistication}

Below the questions belonging to corresponding parts of the Gold-MSI (5-point Likert scale: disagree strongly - agree strongly. Adopted from [71]).

\section{C.1 Music emotions}

\section{$\mathrm{Nr}$ Question}

1 I sometimes choose music that can trigger shivers down my spine.

2 Pieces of music rarely evoke emotions for me.

3 I often pick certain music to motivate or excite me.

4 Music can evoke my memories of past people and places. 


\section{C.2 Active engagement}

\section{Nr Question}

1 I spend a lot of my free time doing music-related activities.

2 I often read or search the Internet for things related to music.

3 I don't spend much of my disposable income on music.

4 Music is kind of an addiction for me - I couldn't live without it.

5 I keep track of new music that I come across (e.g., new artists or recordings).

\section{C.3 Perceptual abilities}

\section{Nr Question}

1 I am able to judge whether someone is a good singer or not.

2 I find it difficult to spot mistakes in a performance of a song even if I know the tune.

3 I can tell when people sing or play out of time with the beat.

4 I can tell when people sing or play out of tune.

5 When I hear a music I can usually identify its genre.

\section{Appendix D: Results}

Below the results of the moderated multiple regression for the mood and genre taxonomy. Step 1 depicts the analyses for the main effects (i.e., general effect of expertise on the user experience without taking into account the different number of categories), and Step 2 depicts the moderator effects (i.e., the effects of expertise on the overchoice effect and the user experience)

\section{D.1 Mood taxonomy \& perceived system usefulness}

\begin{tabular}{|c|c|c|c|c|}
\hline & & $\mathrm{b}$ & $\mathrm{SE} \mathrm{b}$ & $\beta$ \\
\hline \multirow[t]{5}{*}{ Step 1} & Constant & 3.404 & 0.529 & $* * *$ \\
\hline & 6- or 24-item & 0.096 & 0.172 & 0.071 \\
\hline & Active engagement & -0.112 & 0.127 & -0.162 \\
\hline & Emotions & 0.297 & 0.153 & $0.340^{\wedge}$ \\
\hline & Perceptual abilities & -0.059 & 0.127 & -0.074 \\
\hline \multirow[t]{8}{*}{ Step 2} & Constant & 2.144 & 0.755 & $* *$ \\
\hline & 6- or 24-item & 2.446 & 1.036 & $1.807 *$ \\
\hline & Active engagement & -0.28 & 0.174 & -0.404 \\
\hline & Emotions & 0.7 & 0.241 & $0.802 * *$ \\
\hline & Perceptual abilities & -0.036 & 0.152 & -0.045 \\
\hline & Item x Active engagement & 0.366 & 0.258 & 1.016 \\
\hline & Item $\mathrm{x}$ Emotions & -0.657 & 0.306 & $-2.138^{*}$ \\
\hline & Item x Perceptual abilities & -0.203 & 0.271 & -0.606 \\
\hline
\end{tabular}

$R^{2}=0.063$ for step $1, R^{2}=0.160$ for step $2 .{ }^{\wedge} p<0.1, * p<.05, * * p<.01, * * * p<.001$ 


\section{D.2 Mood taxonomy \& perceived system quality}

\begin{tabular}{lllll}
\hline & & $\mathrm{b}$ & $\mathrm{SE} \mathrm{b}$ & $\beta$ \\
\hline Step 1 & Constant & 3.404 & 0.61 & $* * *$ \\
& 6- or 24-item & 0.191 & 0.198 & 0.119 \\
& Active engagement & -0.347 & 0.146 & $-0.422^{*}$ \\
& Emotions & 0.403 & 0.176 & $0.390^{*}$ \\
& Perceptual abilities & -0.001 & 0.147 & -0.001 \\
& Constant & & & \\
Step 2 & 6- or 24-item & 2.864 & 0.874 & $*$ \\
& Active engagement & -0.396 & 0.201 & -0.482 \\
& Emotions & 0.804 & 0.278 & 0.777 \\
& Perceptual abilities & -0.008 & 0.176 & -0.008 \\
& Item x Active engagement & 0.092 & 0.299 & 0.214 \\
& Item x Emotions & -0.65 & 0.354 & $-1.782^{\wedge}$ \\
& Item x Perceptual abilities & -0.06 & 0.313 & -0.152 \\
\hline
\end{tabular}

$R^{2}=0.116$ for step $1, R^{2}=0.200$ for step 2 . $^{\wedge} p<0.1, * p<.05, * * p<.01, * * * p<.001$

\section{D.3 Mood taxonomy \& choice difficulty}

\begin{tabular}{lllll}
\hline & & $\mathrm{b}$ & $\mathrm{SE} \mathrm{b}$ & $\beta$ \\
\hline Step 1 & Constant & 4.906 & 0.634 & $* * *$ \\
& 6- or 24-item & -0.096 & 0.205 & -0.060 \\
& Active engagement & 0.025 & 0.152 & -0.067 \\
& Emotions & -0.069 & 0.183 & -0.067 \\
& Perceptual abilities & -0.114 & 0.153 & -0.121 \\
& Constant & & & \\
Step 2 & 6- or 24-item & 1.967 & 0.900 & $* * *$ \\
& Active engagement & -0.293 & 0.208 & -0.360 \\
& Emotions & 0.320 & 0.287 & 0.313 \\
& Perceptual abilities & -0.027 & 0.182 & -0.029 \\
& Item x Active engagement & 0.734 & 0.308 & 1.735 \\
& Item x Emotions & -0.640 & 0.365 & $-1.775^{\wedge}$ \\
& Item x Perceptual abilities & -0.462 & 0.323 & $-1.178^{*}$ \\
\hline
\end{tabular}

$R^{2}=0.024$ for step $1, R^{2}=0.133$ for step $2 .{ }^{\wedge} p<0.1, * p<.05, * * p<.01, * * * p<.001$ 


\section{D.4 Genre taxonomy \& perceived system usefulness}

\begin{tabular}{lllll}
\hline & & $\mathrm{b}$ & $\mathrm{SE} \mathrm{b}$ & $\beta$ \\
\hline Step 1 & Constant & 3.45 & 0.499 & $* * *$ \\
& 6- or 24-item & 0.327 & 0.134 & $0.174^{*}$ \\
& Active engagement & -0.056 & 0.094 & -0.054 \\
& Emotions & 0.043 & 0.12 & 0.031 \\
& Perceptual abilities & 0.068 & 0.119 & 0.047 \\
& & & & \\
Step 2 & Constant & 4.148 & 0.717 & $* * *$ \\
& 6- or 24-item & -0.863 & 0.975 & -0.458 \\
& Active engagement & -0.037 & 0.136 & -0.036 \\
& Emotions & 0.158 & 0.164 & 0.115 \\
& Perceptual abilities & -0.242 & 0.182 & -0.168 \\
& Item x Active engagement & -0.004 & 0.188 & -0.007 \\
& Item x Emotions & -0.232 & 0.239 & -0.511 \\
& Item x Perceptual abilities & 0.54 & 0.239 & $1.172 *$ \\
\hline
\end{tabular}

$R^{2}=0.032$ for step $1, R^{2}=0.060$ for step $2 .^{\wedge} p<0.1, * p<.05, * * p<.01, * * * p<.001$

\section{D.5 Genre taxonomy \& perceived system quality}

\begin{tabular}{lllll}
\hline & & $\mathrm{b}$ & $\mathrm{SE} \mathrm{b}$ & $\beta$ \\
\hline Step 1 & Constant & 3.313 & 0.631 & $* * *$ \\
& 6- or 24-item & 0.595 & 0.17 & 0.246 \\
& Active engagement & -0.039 & 0.119 & -0.029 \\
& Emotions & 0.027 & 0.152 & 0.015 \\
& Perceptual abilities & 0.049 & 0.15 & 0.027 \\
& Constant & & & \\
& 6- or 24-item 2 & 3.933 & 0.913 & $* * *$ \\
& Active engagement & -0.468 & 1.242 & -0.194 \\
& Emotions & 0.073 & 0.173 & 0.054 \\
& Perceptual abilities & 0.1 & 0.209 & 0.056 \\
& Item x Active engagement & -0.276 & 0.232 & -0.149 \\
& Item x Emotions & -0.18 & 0.239 & -0.271 \\
& Item x Perceptual abilities & 0.56 & 0.304 & -0.232 \\
& & & 0.305 & $0.945^{\wedge}$ \\
\hline
\end{tabular}

$R^{2}=0.060$ for step $1, R^{2}=0.077$ for step 2. ^ $p<0.1 ., * p<.05, * * p<.01, * * * p<.001$

Publisher's note Springer Nature remains neutral with regard to jurisdictional claims in published maps and institutional affiliations.

\section{References}

1. Arnold SJ, Oum TH, Tigert DJ (1983) Determinant attributes in retail patronage: seasonal, temporal, regional, and international comparisons. J Mark Res: 149-157 
2. Back MD, Stopfer JM, Vazire S, Gaddis S, Schmukle SC, Egloff B, Gosling SD (2010) Facebook profiles reflect actual personality, not self-idealization. Psych Sc

3. Baumeister RF, Vohs KD, DeWall CN, Zhang L (2007) How emotion shapes behavior: feedback, anticipation, and reflection, rather than direct causation. Personal Soc Psychol Rev 11(2):167-203

4. Bertin-Mahieux T, Eck D, Mandel M (2011) Automatic tagging of audio: the state-of-the-art. Machine audition: Principles, Algorithms And Systems: $334-352$

5. Boatwright P, Nunes JC (2001) Reducing assortment: an attribute-based approach. J Mark 65(3):50-63

6. Bollen D, Knijnenburg BP, Willemsen MC, Graus M (2010) Understanding choice overload in recommender systems. In: RecSys. ACM, pp 63-70

7. Borle S, Boatwright P, Kadane JB, Nunes JC, Galit S (2005) The effect of product assortment changes on customer retention. Mark Sci 24(4):616-622

8. Bown NJ, Read D, Summers B (2003) The lure of choice. J Behav Decis Mak 16(4):297-308

9. Bravo MJ, Farid H (2006) Object recognition in dense clutter. Percept Psychophys 68(6):911-918

10. Burger J (2010) Personality. PSY 235 Theories of Personality Series. Cengage Learning. ISBN 9780495813965. http://books.google.at/books?id=bZY7I2_8yRMC

11. Chernev A (2003a) When more is less and less is more: the role of ideal point availability and assortment in consumer choice. J Consum Res 30(2):170-183

12. Chernev A (2003b) Product assortment and individual decision processes. J Pers Soc Psychol 85(1):151

13. Craig CS, Ghosh A, McLafferty S (1984) Models of the retail location process-a review. J Retail 60(1):536

14. Delic A, Neidhardt J, Werthner H (2018) Group decision making and group recommendations. In: 2018 IEEE 20th conference on business informatics (CBI), vol 1. IEEE, pp 79-88

15. Dhar R (1996) The effect of decision strategy on deciding to defer choice. J Behav Decis Mak 9(4):265281

16. Dhar R (1997) Consumer preference for a no-choice option. J Consum Res 24(2):215-231

17. Dhar R, Nowlis SM (1999) The effect of time pressure on consumer choice deferral. J Consum Res 25(4):369-384

18. Diehl K, Poynor C (2010) Great expectations?! assortment size, expectations, and satisfaction. J Mark Res 47(2):312-322

19. Dreze X, Hoch SJ, Purk ME (1995) Shelf management and space elasticity. J Retail 70(4):301-326

20. Easterbrook JA (1959) The effect of emotion on cue utilization and the organization of behavior. Psych $\operatorname{Rev} 66(3): 183$

21. Elahi M, Braunhofer M, Ricci F, Tkalcic M (2013) Personality-based active learning for collaborative filtering recommender systems. In: AI* IA advances in artificial intelligence. Springer, p 2013

22. Fasolo B, Hertwig R, Huber M, Ludwig M (2009) Size, entropy, and density: what is the difference that makes the difference between small and large real-world assortments? Psychol Mark 26(3):254-279

23. Ferwerda B (2015) The soundtrack of my life: adjusting emotion of music. In: Proceedings of the 1st workshop collaborating with intelligent machines, Seoul, South Korea

24. Ferwerda B (2016) Improving the user experience of music recommender systems through personality and cultural information. PhD. Johannes Kepler University Linz, Linz, Austria

25. Ferwerda B, Graus M (2018) Predicting musical sophistication from music listening behaviors: a preliminary study. arXiv: 1808.07314

26. Ferwerda B, Schedl M (2014) Enhancing music recommender systems with personality information and emotional states: a proposal. In: Proceedings of the 2nd workshop emotions and personality in personalized services (EMPIRE 2014), Aalborg, Denmark, pp 1613-0073

27. Ferwerda B, Schedl M (2016a) Investigating the relationship between diversity in music consumption behavior and cultural dimensions: a cross-country analysis. In: UMAP (extended proceedings)

28. Ferwerda B, Schedl M (2016b) Personality-based user modeling for music recommender systems. In: Joint European conference on machine learning and knowledge discovery in databases. Springer, pp 254-257

29. Ferwerda B, Tkalcic M (2018a) Predicting users' personality from instagram pictures: using visual and/or content features? In: The 26th conference on user modeling, adaptation and personalization, Singapore (2018)

30. Ferwerda B, Tkalcic M (2018b) You are what you post: what the content of instagram pictures tells about users' personality. In: The 23rd international on intelligent user interfaces

31. Ferwerda B, Schedl M, Tkalcic M (2015a) Predicting personality traits with instagram pictures. In: Proceedings of the 3rd workshop on emotions and personality in personalized systems 2015, EMPIRE '15, pages 7-10, New York, NY, USA, ACM. ISBN 978-1-4503-3615-4. https://doi.org/10.1145/2809643.2809644 
32. Ferwerda B, Schedl M, Tkalcic M (2015b) Personality \& emotional states: understanding users' music listening needs. UMAP

33. Ferwerda B, Yang E, Schedl M, Tkalcic M (2015c) Personality traits predict music taxonomy preferences. In: CHI'15 extended abstracts on human factors in computing systems. ACM

34. Ferwerda B, Graus MP, Vall A, Tkalcic M, Schedl M (2016a) The influence of users' personality traits on satisfaction and attractiveness of diversified recommendation lists, pp 43-47

35. Ferwerda B, Schedl M, Tkalcic M (2016b) Personality traits and the relationship with (non-)disclosure behavior on facebook. In: Proceedings of the international workshop on modeling social media. ACM

36. Ferwerda B, Schedl M, Tkalcic M (2016c) Using instagram picture features to predict users' personality. In: MultiMedia modeling. Springer, pp 850-861

37. Ferwerda B, Vall A, Tkalcic M, Schedl M (2016d) Exploring music diversity needs across countries. In: Proceedings of the 2016 conference on user modeling adaptation and personalization. ACM, pp 287-288

38. Ferwerda B, Tkalcic M, Schedl M (2017a) Personality traits and music genres: what do people prefer to listen to? In: Proceedings of the 25th conference on user modeling, adaptation and personalization. ACM, pp 285-288

39. Ferwerda B, Tkalcic M, Schedl M (2017b) Personality traits and music genre preferences: how music taste varies over age groups. In: Proceedings of the 1st workshop on temporal reasoning in recommender systems (RecTemp) at the 11th ACM conference on recommender systems, Como, August 31, 2017

40. Fu Z, Lu G, Ting KM, Zhang D (2011) A survey of audio-based music classification and annotation. Multimedia, IEEE Transactions on: 303-319

41. Golbeck J, Robles C, Edmondson M, Turner K (2011) Predicting personality from twitter. In: Privacy, security, risk and trust (passat), 2011 ieee third international conference on and 2011 ieee third international conference on social computing (socialcom). IEEE, pp 49-156

42. Gosling SD, Gaddis S, Vazire S et al (2007) Personality impressions based on facebook profiles. ICWSM

43. Gourville JT, Soman D (2005) Overchoice and assortment type: when and why variety backfires. Market Sci 24(3):382-395

44. Greenberg DM, Müllensiefen D, Lamb ME, Rentfrow PJ (2015) Personality predicts musical sophistication. J Res Pers 58:154-158

45. Gross JJ, John OP (1998) Mapping the domain of expressivity: multimethod evidence for a hierarchical model. J Pers Soc Psychol: 170

46. Haynes GA (2009) Testing the boundaries of the choice overload phenomenon. The effect of number of options and time pressure on decision difficulty and satisfaction. Psychol Mark 26(3):204-212

47. van Herpen E, Diehl K, Poynor C (2008) Arranged to distraction: how categorizing products with complements versus substitutes alters the experience of product choice. Adv Consum Res 35:80-83

48. Hsee CK, Leclerc F (1998) Will products look more attractive when presented separately or together? J Consum Res 25(2):175-186

49. Hu R, Pu P (2009) Acceptance issues of personality-based recommender systems. In: RecSys. ACM, pp 221-224

50. Hutchinson $\mathrm{J}$ (2005) Is more choice always desirable? evidence and arguments from leks, food selection, and environmental enrichment. Biol Rev 80(1):73-92

51. Iyengar SS, Lepper MR (2000) When choice is demotivating can one desire too much of a good thing? J Pers Soc Psychol 79(6):995

52. Iyengar SS, Huberman G, Jiang W (2004) How much choice is too much? contributions to 401 (k) retirement plans. Pension design and structure: new lessons from behavioral finance: $83-95$

53. Iyengar SS, Wells RE, Schwartz B (2006) Doing better but feeling worse looking for the "best" job undermines satisfaction. Psychol Sci 17(2):143-150

54. Janiszewski C (1998) The influence of display characteristics on visual exploratory search behavior. J Consum Res 25(3):290-301

55. John OP, Donahue EM, Kentle RL (1991) The big five inventory: versions 4a and 54, institute of personality and social research, UC Berkeley

56. Jung (1976) Psychological Types. Number v. 6 in Bollingen Series No. 20. Princeton University Press, Princeton. ISBN 9780691018133

57. Kahn BE (1995) Consumer variety-seeking among goods and services: an integrative review. J Retail Consum Serv 2(3):139-148

58. Kahn BE, Wansink B (2004) The influence of assortment structure on perceived variety and consumption quantities. J Consum Res 30(4):519-533

59. Kemp AE (1996) The musical temperament: psychology and personality of musicians. Oxford University Press, London

60. Kittur A, Chi EH, Suh B (2008) Crowdsourcing user studies with mechanical turk. In: Proceedings of the SIGCHI conference on human factors in computing systems. ACM, pp 453-456 
61. Knijnenburg BP, Willemsen MC, Gantner Z, Soncu H, Newell C (2012) Explaining the user experience of recommender systems. User Model User-Adap Inter 22(4-5):441-504

62. Knoll N, Burkert S, Schwarzer R (2006) Reciprocal support provision: personality as a moderator? Eur J Personal 20(3):217-236

63. Koelemeijer K, Oppewal H (1999) Assessing the effects of assortment and ambience: a choice experimental approach. J Retail 75(3):319-345

64. Langner T, Krengel M (2013) The mere categorization effect for complex products: the moderating role of expertise and affect. J Bus Res 66(7):924-932

65. Lay A, Ferwerda B (2018) Predicting users' personality based on their 'liked' images on instagram. In: The 23rd international on intelligent user interfaces

66. Leith KP, Baumeister RF (1996) Why do bad moods increase self-defeating behavior? emotion, risk tasking, and self-regulation. J Pers Soc Psychol 71(6):1250

67. Lonsdale AJ, North AC (2011) Why do we listen to music? a uses and gratifications analysis. Br J Psychol 102(1):108-134

68. Mazursky D, Jacoby J (1986) Exploring the development of store images. J Retail 62(2):145-165

69. McCrae RR, John OP (1992) An introduction to the five-factor model and its applications. Journal Pers 60(2):175-215

70. Mogilner C, Rudnick T, Iyengar SS (2008) The mere categorization effect: how the presence of categories increases choosers' perceptions of assortment variety and outcome satisfaction. J Consum Res 35(2):202-215

71. Müllensiefen D, Gingras B, Musil J, Stewart L (2014) The musicality of non-musicians: an index for assessing musical sophistication in the general population. PloS one 9(2):e89642

72. Oppewal H, Koelemeijer K (2005) More choice is better effects of assortment size and composition on assortment evaluation. Int J Res Mark 22(1):45-60

73. Park G, Schwartz HA, Eichstaedt JC, Kern ML, Kosinski M, Stillwell DJ, Ungar LH, Seligman MEP (2014) Automatic personality assessment through social media language

74. Perruchet P, Rey A, Hivert E, Paction S (2006) Do distractors interfere with memory for study pairs in associative recognition? Mem Cogn

75. Quercia D, Kosinski M, Stillwell D, Crowcroft J (2011) Our twitter profiles, our selves: predicting personality with twitter. In: Privacy, security, risk and trust (passat), 2011 ieee third international conference on and 2011 ieee third international conference on social computing (socialcom). IEEE, pp 180185

76. Rawlings D, Ciancarelli V (1997) Music preference and the five-factor model of the neo personality inventory. Psychol Music 25(2):120-132

77. Redelmeier DA, Shafir E (1995) Medical decision making in situations that offer multiple alternatives. Jama 273(4):302-305

78. Rentfrow PJ, Gosling SD (2003) The do re mi's of everyday life: the structure and personality correlates of music preferences. J Pers Soc Psychol 84(6):1236

79. Rentfrow PJ, Goldberg LR, Zilca R (2011) Listening, watching, and reading: the structure and correlates of entertainment preferences. J Pers 79(2):223-258

80. Reutskaja E, Hogarth RM (2009) Satisfaction in choice as a function of the number of alternatives: when "goods satiate". Psychol Mark 26(3):197-203

81. Ross C, Orr ES, Sisic M, Arseneault JM, Simmering MG, Robert Orr R (2009) Personality and motivations associated with facebook use. Comput Hum Behav 25(2):578-586

82. Schedl M, Ferwerda B (2017) Large-scale analysis of group-specific music genre taste from collaborative tags. In: 2017 IEEE international symposium on multimedia (ISM). IEEE, pp 479-482

83. Schedl M, Lemmerich F, Ferwerda B, Skowron M, Knees P (2017) Indicators of country similarity in terms of music taste, cultural, and socio-economic factors. In: Multimedia (ISM) IEEE international symposium on. IEEE, p 2017

84. Scheibehenne B, Greifeneder R, Todd PM (2009) What moderates the too-much-choice effect? Psych Market 26(3):229-253

85. Scheibehenne B, Greifeneder R, Todd PM (2010) Can there ever be too many options? a meta-analytic review of choice overload. J Consum Res 37(3):409-425

86. Schwartz B (2004a) The paradox of choice. Ecco New York

87. Schwartz B (2004b) The tyranny of choice. Scientific American-American Edition 290(4):70-75

88. Shah AM, Wolford G (2007) Buying behavior as a function of parametric variation of number of choices. Psychol Sci 18(5):369-370

89. Skowron M, Tkalčič M, Ferwerda B, Schedl M (2016) Fusing social media cues: personality prediction from twitter and instagram. In: Proceedings of the 25th international conference companion on world wide web, pp 107-108. International world wide web conferences steering committee 
90. Skowron M, Lemmerich F, Ferwerda B, Schedl M (2017) Predicting genre preferences from cultural and socio-economic factors for music retrieval. In: European conference on information retrieval. Springer

91. Sloot LM, Fok D, Verhoef PC (2006) The short-and long-term impact of an assortment reduction on category sales. J Mark Res 43(4):536-548

92. Tkalcic M, Kunaver M, Tasic J, Košir A (2009) Personality based user similarity measure for a collaborative recommender system. In: Proceedings of the 5th workshop on emotion in human-computer interaction-real world challenges, pp 30-37

93. Tkalcic M, Kunaver M, Košir A, Tasic J (2011) Addressing the new user problem with a personality based user similarity measure. In: First international workshop on DEMRA 2011, p 106

94. Tkalcic M, Ferwerda B, Hauger D, Schedl M (2015) Personality correlates for digital concert program notes. UMAP: 1-6

95. Tkalcic M, Delic A, Felfernigab A (2018) Personality, emotions, and group dynamics. Springer, Berlin

96. Yun JT, Duff BRL (2017) Is utilizing themes an effective scheme? choice overload and categorization effects within an extensive online choice environment. Comput Hum Behav 74:205-214

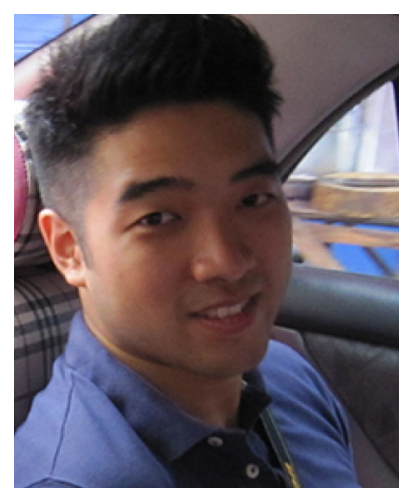

Bruce Ferwerda an Assistant Professor in the Department of Computer Science and Informatics at the School of Engineering of Jönköping University in Sweden. He received his PhD from the Johannes Kepler University Linz in Austria, an MSc from Eindhoven University of Technology in the Netherlands, and a BEng of the Amsterdam University of Applied Sciences in the Netherlands. His main research interests include: humancomputer interaction, psychology, personalization, persuasive technologies, and recommender systems.

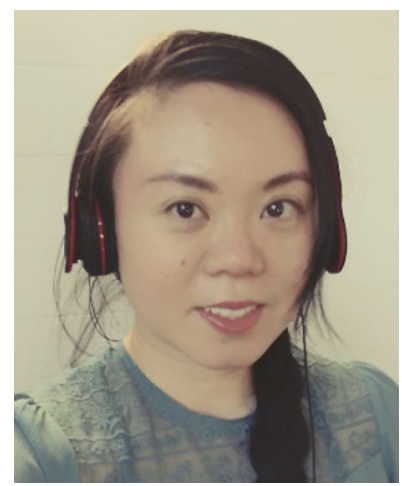

Emily Yang is a user experience researcher at Paychex, a former radio DJ, and an overall music nerd. She is passionate about building meaningful and usable technology through better understanding of users. She holds a master's degree in Human-Technology Interaction from Eindhoven University of Technology. 


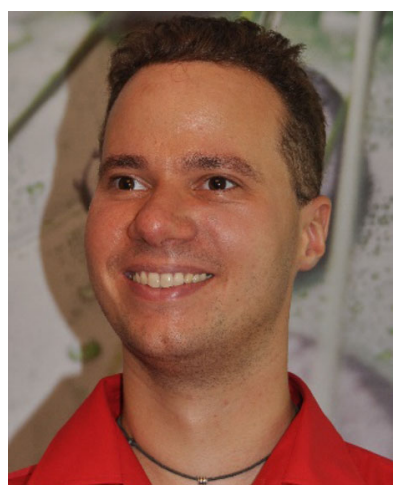

Markus Schedl is an Associate Professor at the Johannes Kepler University Linz / Institute for Computational Perception. He graduated in Computer Science from the Vienna University of Technology and earned his Ph.D. in Computer Science from the Johannes Kepler University Linz. Markus further studied International Business Administration at the Vienna University of Economics and Business Administration as well as at the Handelshogskolan of the University of Gothenburg, which led to a Master?s degree. His main research interests include web and social media mining, information retrieval, multimedia, and music information research.

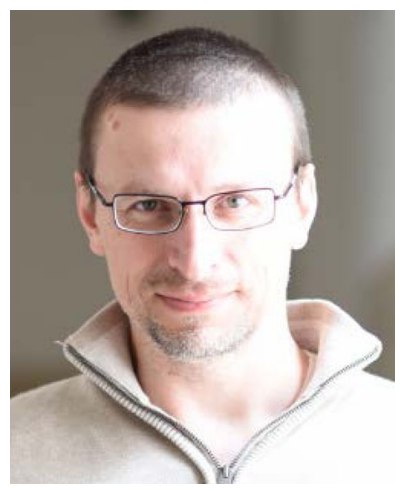

Marko Tkalcic is assistant professor at the Faculty of Computer Science at the Free University of BozenBolzano in Italy. His research focuses on psychological aspects of personalization in connection with computational models. Specific interests include the usage of psychological models (e.g. personality, emotions etc.) for improving personalized applications (e.g. recommender systems) and the usage of social media to infer the psychological models. He is a member of the editorial board of the UMUAI journal. Marko Tkalcic has published in prestigious journals, such as UMUAI, IEEE Transactions on Affective Computing, Elsevier Information Sciences, Multimedia Tools and Applications, and IEEE Transactions on Multimedia. 


\title{
Affiliations
}

\section{Bruce Ferwerda $^{1}$ (D) $\cdot$ Emily Yang $^{2} \cdot$ Markus SchedI $^{2} \cdot$ Marko Tkalcic $^{3}$}

\author{
Emily Yang \\ emily@emzyne.net
}

Markus Schedl

markus.schedl@jku.at

Marko Tkalcic

marko.tkalcic@unibz.it

1 Department of Computer Science and Informatics, Jönköping University, Jönköping, Sweden

2 Institute for Computational Perception, Johannes Kepler University, Linz, Austria

3 Faculty of Computer Science, Free University of Bozen-Bolzano, Bolzano, Italy 